\title{
The influence of global climate change on the environmental fate of persistent organic pollutants: A review with emphasis on the Northern Hemisphere and the Arctic as a receptor
}

\author{
Authors: Jianmin $\mathrm{Ma}^{1,5}$, Hayley Hung ${ }^{2}$, Robie W. Macdonald ${ }^{3,4}$ \\ Affiliations: \\ ${ }^{1}$ Key Laboratory for Environment Pollution Prediction and Control, Gansu Province, \\ Department of Environmental Science and Engineering, Lanzhou University, China \\ ${ }^{2}$ Air Quality Processes Research Section, Science and Technology Branch, Environment \\ and Climate Change Canada, 4905 Dufferin Street, Toronto, Ontario, M3H 5T4 Canada \\ ${ }^{3}$ Department of Environment and Geography, Centre for Earth Observation Science, \\ University of Manitoba, Manitoba R3T 2N2, Canada \\ ${ }^{4}$ Fisheries and Oceans Canada, Institute of Ocean Sciences, Sidney, British Columbia \\ V8L 4B2, Canada. \\ ${ }^{5}$ CAS Center for Excellence in Tibetan Plateau Earth Sciences, Beijing 100101, China

\section{Revised and resubmitted to: Global and Planetary Change}

Key words: Climate, toxic chemicals, global distribution, bioaccumulation, Arctic 


\begin{abstract}
Following worldwide bans and restrictions on the use of many persistent organic pollutants (POPs) from the late 1970s, their regional and global distributions have become governed increasingly by phase partitioning between environmental reservoirs, such as air, water, soil, vegetation and ice, where POPs accumulated during the original applications. Presently, further transport occurs within the atmospheric and aquatic reservoirs. Increasing temperatures provide thermodynamic forcing to drive these chemicals out of reservoirs, like soil, vegetation, water and ice, and into the atmosphere where they can be transported rapidly by winds and then recycled among environmental media to reach locations where lower temperatures prevail (e.g., polar regions and high elevations). Global climate change, widely considered as global warming, is also manifested by changes in hydrological systems and in the cryosphere; with the latter now exhibiting widespread loss of ice cover on the Arctic Ocean and thawing of permafrost. All of these changes alter the cycling and fate of POPs. There is abundant evidence from observations and modeling showing that climate variation has an effect on POPs levels in biotic and abiotic environments. This article reviews recent progress in research on the effects of climate change on POPs with the intention of promoting awareness of the importance of interactions between climate and POPs in the geophysical and ecological systems.
\end{abstract}

\title{
Table of Contents
}

1. Introduction

2. How climate change interacts with POPs

2.1 Temperature-dependent physicochemical properties of POPs

2.2 Terrestrial and fresh water environments

\subsection{Atmosphere}




\subsection{Marine environment}

\subsection{Cryospheric environment}

3. Searching for climate change signals in POPs monitoring data

4. Model simulation and prediction of future POPs trends under projected climate change and emission scenarios

5. Food web and wildlife exposure risk to POPs under a changing climate

6. Conclusions

7. Acknowledgements

8. References

\section{Introduction}

Persistent organic pollutants (POPs) are toxic substances produced by industry and released to the environment either deliberately or unintentionally by human activities. Within the environment, POPs are resistant to degradation, and can, therefore, accumulate over long periods of time in solid, liquid or gas-phase reservoirs from which they enter food webs, posing risks to ecosystems and human health. These contaminants include industrial chemicals [such as polychlorinated biphenyls (PCBs)], pesticides [such as dichlorodiphenyltrichloroethane (DDT)], and unintentionally produced chemicals (such as dioxins and furans); among which are compounds with exceptional toxicity to human development [e.g., 2,3,7,8 -tetrachlorodibenzo- $p$-dioxin (2,3,7,8-TCDD)] (Berg et al., 2006). Owing to their persistence, POPs can transport long distances in the atmosphere and oceans, thence to accumulate in water, sediments, vegetation and in the crysosphere (snow, ice, permafrost) (Muir and Nordstrom, 1994; Mackay and Wania, 1995; Wania and Mackay, 1996; Macdonald et al., 2005; Bailey et al., 2000; Grannas et al., 2013). Global thermodynamic forcing by temperature gradients has been proposed as a leading mechanism to enhance the accumulation of semivolatile chemicals in cold environments (Wania and Mackay, 1996). Ample evidence has been collected to 
demonstrate that remote, pristine locations, like the Arctic and high mountains, far from the predominant POPs sources, reflect this cold-trapping process and have been widely contaminated by POPs (Goldberg,1975; Ottar, 1981; Meijer et al., 2003; Hung et al., 2010). Recently, the European Union instigated investigations into linkages among climate change, persistent toxic chemicals, and ecosystem risks in the Arctic through the ArcRisk (Arctic Health Risks) project, with the intent of furthering the understanding of POPs cycling in the environment and biota under a warming Arctic (http://www.arcrisk.eu/about-us/). The cycling of POPs is driven primarily by physicochemical properties of the chemicals (volatility, partitioning among phases) and environmental factors, such as temperature, precipitation, winds, and currents (Simonich and Hites, 1995; Dachs et al., 2002; Gobas and Maclean, 2003; Stemmler and Lammel, 2009; Meijer et al., 2009). In addition to these physical factors, biogeochemical cycles also play crucial roles because they provide transport pathways (e.g., Blais et al., 2007) and mechanisms to concentrate POPs (Lohmann et al., 2007; Nizzetto et al., 2010; Macdonald et al., 2002). Efforts have been made nationally and internationally to regulate or phase out POPs through domestic chemical control initiatives and international environmental treaties, such as the United Nations Environment Programme (UNEP) Stockholm Convention on Persistent Organic Pollutants and the United Nations Economic Commission for Europe (UNECE) POPs Protocol of the Convention on Long-range Transboundary Air Pollution. The Stockholm Convention on POPs, which came into effect in 2004, initially identified twelve chemicals or chemical groups (the so called Dirty Dozen) for regulation and elimination of production and use (www.pops.int). As a result of these and other control efforts, the environmental levels of legacy POPs 
have been declining worldwide, demonstrating some success of POPs regulations (Kong et al., 2014). On the other hand, the number of chemicals added to the list of POPs under the Stockholm Convention has been increasing, with 26 chemicals or chemical groups presently listed for elimination (see http://chm.pops.int/default.aspx).

While long-term POPs monitoring data show generally decreasing patterns during the past two decades for regulated (legacy) POPs, the influence of climate change (referred to as $\mathrm{CC}$ hereafter) on temporal and spatial distributions of POPs in biotic and abiotic environments poses a new challenge to governments and scientists. For many industrial POPs and pesticides, significant release to the environment started after World War II and peaked during 1970 - 1990 (Li and Macdonald, 2005). Once released at their sources, POPs were transported by winds and, following atmospheric circulation patterns, arrived within days at remote regions where they had never been used. In remote places like the Arctic, lower temperatures promoted the partitioning of POPs from air to liquid or solid, and thus POPs were deposited in snow, ice, vegetation, and soil where prevailing cold temperatures helped to preserve them and, therefore, extend their residence time in the environment. The distribution of POPs in the global environment can be attributed largely to their physiochemical properties, which are temperature dependent and often parameterized by linear relationships with temperature. With warming, POPs that had been sequestered in water or terrestrial surfaces by low temperatures tend to return to the atmosphere. The thawing of permafrost or melting of sea-ice and glaciers due to warming provides another means for historically archived contaminants to mobilize into aquatic systems (e.g., Blais et al., 2001; Bogdal et al., 2010). Subsequent to entry into aquatic systems, released POPs may then enter the food chain and become biomagnified in top 
predators. There is a growing body of evidence that $\mathrm{CC}$ results in the release of POPs locally, regionally and globally from containment in historically-accumulated reservoirs. The CC-induced release of archived POPs, together with direct and indirect alterations in biogeochemical cycles, also due to $\mathrm{CC}$, then provides opportunities for 'surprises' that could undermine global efforts to reduce environmental and human exposure to these toxic chemicals. The daunting complexity of the global environment into which POPs are released (Figure 1, top panel, showing the Northern Hemisphere only) has been simplified by viewing the system as a series of arrows signifying fluxes, and boxes signifying reservoirs (Figure 1, bottom panel). These fluxes (release, transport, degradation) and reservoirs (soil, vegetation, water, ice) are all vulnerable to $\mathrm{CC}$, which then leads to the re-distribution of POPs.

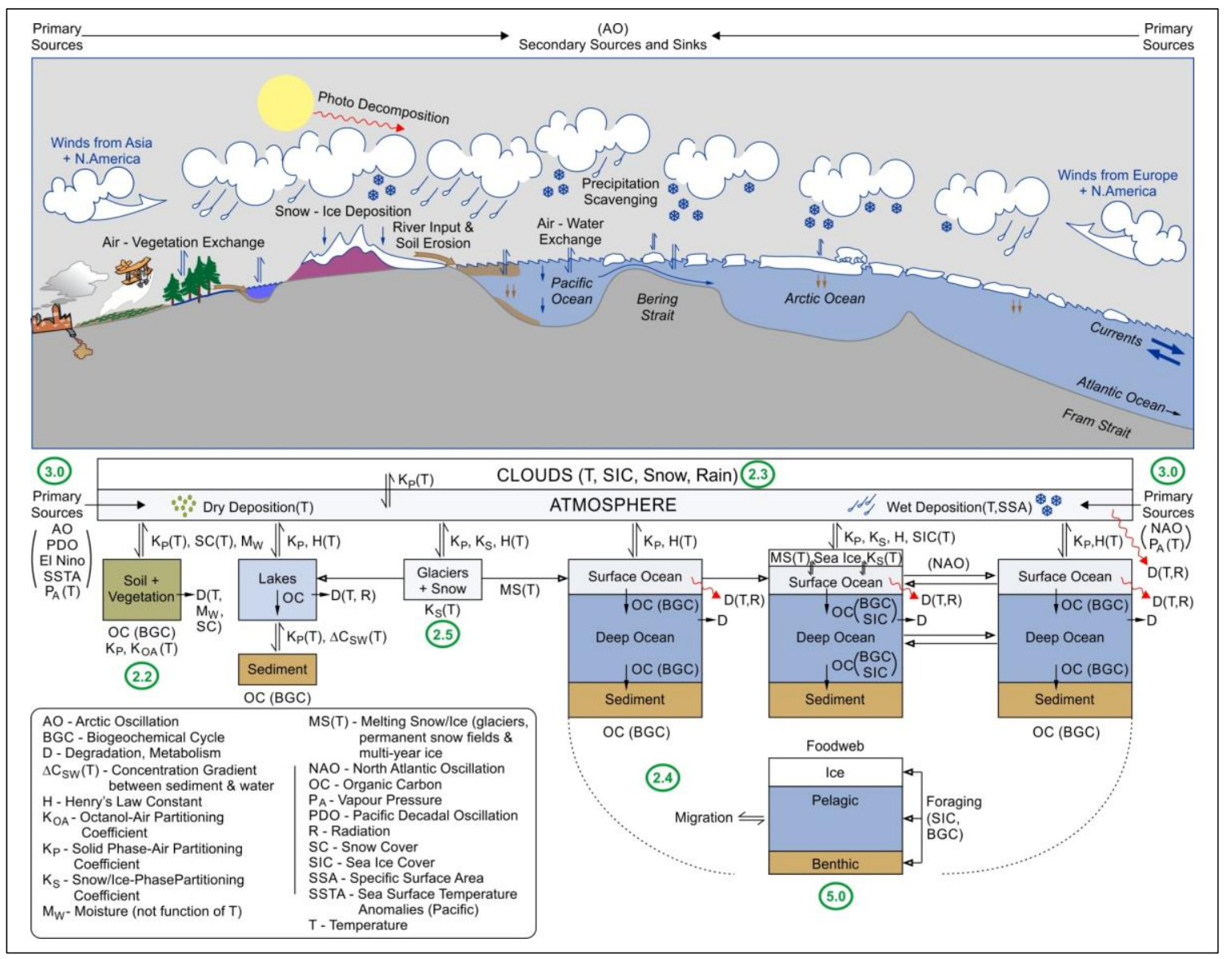


Figure 1. A simplified schematic view of the Northern Hemisphere into which POPs are released (top panel). Release points for POPs lie predominantly in temperate regions from which the POPs spread out into the environment on winds and currents. Initially, POPs transport is affected by large-scale atmospheric climate variability patterns, like the NAO or PDO, but as they become widely distributed through environmental and biological pathways, they become subject to many climate variables, in particular temperature, the hydrological cycle and the organic carbon cycle. Depending strongly on their physicochemical properties and ease of degradation, POPs interact variously with the Earth's surface along the transport routes as shown by flux arrows. A common approach to modeling represents the Earth system as a set of arrows to indicate POPs fluxes (releases, transport, losses) and boxes to indicate POPs reservoirs (air, water, soil, vegetation, ice) (bottom panel). The impact of CC on the fate of POPs can then be projected; for example, by evaluating the effect of increasing temperature on partitioning between phases and on degradation rates, or the effects of loss of compartment size due to loss of vegetation, or the thawing of snow and ice, or the alteration of foodweb structures and foraging. The circled numbers in the bottom panel refer to the sections where this part of the diagram is predominantly discussed. Only selected large-scale climate variability patterns discussed in the text are represented. Terrestrial-related processes (air-vegetation exchange, snow-ice deposition, snow/ice melting and runoff, river input and soil erosion to lakes/oceans) apply to all global regions but for simplicity are represented only for the Pacific Ocean.

Given the dramatic changes now unfolding in the cryosphere and elsewhere, an increasing number of observational and modeling studies over the past decade have focused on what climate change and variability imply for the transport, deposition and cycling of POPs (and other contaminants) in abiotic and biotic systems (e.g., Lucia et al., 2015; Manciocco et al., 2014; Armitage et al., 2013; McKinney, 2012; Kallenborn et al., 2012; Bidleman et al., 2012; Sumaila et al., 2011; Bustnes et al., 2010; Bogdal et al., 2009, 2010; McKinney et al,, 2009; Becker et al., 2008, 2012; Geisz et al., 2008; Thies et al., 2007; Eckhardt et al., 2007; Garrett and Zhao, 2006; Stern et al., 2005; Ma et al., 2005, 2006, 2010, 2011; MacLeod, 2005; Lamon et al., 2009; Wang et al., 2010a,b; Komprda et al., 2013; Wöhrnschimmel et al., 2013; Rigét et al., 2010, 2013; Octaviani et al., 2015; Zhao et al., 2015). Likewise, reviews have highlighted the wide variety of potential CC-contaminant interactions (Noyes and Lima, 2015; Teran et al., 2012; UNEP/AMAP , 2011; Kallenborn et al., 2011; Rockström et al., 2009a, b; Dauvin , 2007; 
Schindler and Smol, 2006; Watson et al., 2005; Macdonald et al., 2005; Schiedek et al., 2007; Noyes et al., 2009; Armitage, et al., 2011; Kallenborn et al., 2012; Teng et al., 2012; Gouin et al., 2013; Grannas et al., 2013). Climate variability and climate change operate on almost every aspect of a POP's lifetime in the environment. However, due to knowledge gaps in understanding the complex dynamic exchange and transport, toxicological, and biological processes in POPs contamination to the environment, and the lack of sufficient monitoring data, many of the modeled or predicted effects of $\mathrm{CC}$ on POPs have not yet been confirmed (Zhao et al., 2015).

In the present article, we aimed to provide an overview of recent progresses in understanding the associations between POPs in biotic and abiotic environments and CC. The article is particularly aimed to inform geophysical and ecological scientists about the importance of climate variability and change to the cycling and fate of POPs in the environment.

\section{How climate change interacts with POPs}

2.1 Temperature-dependent physicochemical properties of POPs

Once released into the environment from applications in agriculture, commerce and industry, POPs immediately begin to distribute themselves among available reservoirs, such as air, water, soil, vegetation, snow and ice. The exchange of POPs between these reservoirs depends critically on the physicochemical properties of a given POP and environmental conditions. With respect to the redistribution of POPs, the important intrinsic physicochemical properties, including vapour pressure $\left(\mathrm{P}_{\mathrm{A}}\right)$, Henry's Law constant $(\mathrm{H})$, partition coefficients for octanol-air $\left(\mathrm{K}_{\mathrm{OA}}\right)$ and octanol-water $\left(\mathrm{K}_{\mathrm{OW}}\right)$, and 
susceptibility to degradation or transformation (e.g., photolysis, metabolism, hydrolysis), provide kinetic controls on how long a chemical can remain in any given compartment. These thermodynamic and kinetic properties, which are functions of temperature (T), are often parameterized using linear regressions or other relationships between the property in question and temperature (Table 1; Wania et al., 1998; Shoeib and Harner, 2002; Cetin et al., 2006; Jantunen and Bidleman, 2006). Negative linear regression relationships between $\ln \mathrm{P}_{\mathrm{A}}$ and 1/T and positive regression relationships between $\log \mathrm{K}_{\mathrm{OA}}$ and 1/T (Table 1) indicate that increasing temperature enhances volatilization by increasing $\mathrm{P}_{\mathrm{A}}$ and decreasing $\mathrm{K}_{\mathrm{OA}}$. An increase in $\mathrm{T}$ of $1{ }^{\circ} \mathrm{C}$ has been estimated to increase the volatility of a typical POP by 10-15\% (Lamon et al., 2009). Such an increase in T could result in a $7.8 \%$ and $8.5 \%$ increase, respectively, for the total yearly volatilization fluxes of hexachlorobenzene (HCB) and dichlorodiphenyldichloroethylene (DDE), a degradation product of DDT (Komprda et al., 2013). Further temperature increases by 2 and $3^{\circ} \mathrm{C}$ could lead, respectively, to increases in volatilization fluxes for $\mathrm{HCB}$ of $8.6 \%$ and $9.3 \%$, and for DDE of $9.4 \%$ to $10.4 \%$. Locally, atmospheric temperatures may increase episodically up to $10^{\circ} \mathrm{C}$ to $15^{\circ} \mathrm{C}$, which would double the $\mathrm{P}_{\mathrm{A}}$ of PCB-153 with a relatively higher internal energy of vaporization (91.6 $\mathrm{kJ} \mathrm{mol}^{-1}$, Lamon et al., 2009)

Rising temperatures will increase Henry's law constants, promoting higher partitioning from water into air for POPs. These properties have also been linked with POPs atmospheric and oceanic transport, global distribution, partitioning between environmental media, secondary emission, and bioaccumulation in food webs (Macdonald et al., 2005; Lamon et al., 2009; Kallenborn et al., 2012; Bustnes et al., 2010). The presence of virtually every widely-used POP in the ambient environment of 
remote areas like the Arctic, demonstrates the efficacy of atmospheric and oceanic transport to these remote areas from the temperate regions where most of these substances have been released (Figure 1). A widely-cited hypothesis to explain why some POPs are found in remote, cold environments at concentrations that cause concern is the effect of low temperatures on physicochemical properties that enhance deposition within such environments (Mackay and Wania, 1995). This process has been termed "cold condensation" (Ottar, 1981), but perhaps a better way describing it would be “global fractionation” (Wania and Mackay, 1993, 1996), or “cold trapping” (Rahn and Heidam, 1981). These terms refer not just to condensation but to a set of properties that favour partitioning from air to water, snow or solids at low temperatures. Ambient atmospheric monitoring in the Arctic and other northern territories has revealed higher proportions of compounds with relatively higher volatility at environmental temperatures (Wania and Mackay, 1993). von Waldow et al (2010) proposed a differential removal of POPs, which better explained the long-range transport (LRT) and fractionation of PCBs in the Northern Hemispheric atmosphere than did global fractionation. With differential removal, the latitudinal fractionation of PCBs is driven by variation in loss rates (deposition and degradation) in the atmosphere along the transport pathway from emission to remote deposition, rather than just air temperature, although temperature clearly affects loss rates in transport. As shown in Table 1, when temperature, T, increases, the first term on the right hand side of $\log P_{\mathrm{A}}$ equation increases, resulting in an increase of vapour pressure, whereas, $\log \mathrm{K}_{\mathrm{OA}}$ becomes smaller with increasing $\mathrm{T}$; both of these changes favour higher gaseous concentrations in air. On the other hand, chemicals with low $\mathrm{P}_{\mathrm{A}}$ and high $\mathrm{K}_{\mathrm{OA}}$ tend to remain in the source regions because the former favours 
low gaseous concentrations in air and the latter results in greater tendency to sorb to air-borne particles, which can be more easily deposited close to source. Abundant observations and modeling studies have revealed that 'heavier' chemicals are less prone to be transported to remote pristine areas (Wania and Mackay, 1993, 1996; Wania and Su, 2004).

Primary emission of POPs continues to contribute to atmospheric trends through volatilization from poorly-contained contaminated materials and stockpiles. These sources, which account for the majority of ongoing primary emissions (Breivik et al., 2007), are also increased by rising temperatures (Lamon et al., 2009; Gouin et al., 2013; Wöhrnschimmel et al., 2013), which led Lamon et al. to assume that the strength of primary emissions for any given $\mathrm{PCB}$ congener would be proportional to $\mathrm{P}_{\mathrm{A}}$, expressed by the relationship $E_{T}=E_{T-r e f} \exp \left\lfloor\Delta U_{A}\left(1 / T_{r e f}-1 / T\right) / R\right\rfloor$, where $T_{\text {ref }}$ is the reference temperature $\left(\mathrm{C}^{\mathrm{o}}\right)$, $\mathrm{T}$ is the environmental temperature, $\Delta \mathrm{U}_{\mathrm{A}}$ is the internal energy of vaporization, $\mathrm{R}$ is the ideal gas constant and $E_{T}$ and $E_{T \text {-ref }}$ are the volatilization emission rates at the respective temperatures. For PCB-153, a relatively hydrophobic congener, a temperature increase of $4{ }^{\circ} \mathrm{C}$ above the reference temperature would lead to an approximate 1.7-fold increase in emission rate (Gouin et al., 2013). This increase alone would dominate all of the other processes known to have the potential to contribute to air concentration trends under climate warming.

\subsection{Terrestrial and fresh water environments}

Since POPs tend to partition from gas and liquid phases to organic phases (Nizzetto et al., 2010), the spatial distribution of atmospheric POPs is also driven in part by gradients in 
organic carbon content in soils (Simonich and Hites 1994; Gobas and McLean, 2003; Macdonald et al. 2005; Cousins et al., 1999; Zheng et al., 2014). Field experiment (Moeckel et al., 2008) has suggested that in the year of 2000, about $50 \%$ of the total annual anthropogenic emission of PCB-153 was archived in storage compartments (soil or sediments) subject to organic carbon (OC) distributions. Soils and plants act as important reservoirs because POPs tend to be preferentially adsorbed or partitioned onto OC or carbon-rich particles contained within terrigenous systems. Compared with fluids like the atmosphere and water bodies, which transport POPs that have entered the environment, organic carbons in soils and sediment provide stationary "end points" where POPs may reside for longer periods of time. For most legacy POPs whose use and production have been banned worldwide, the mass of legacy chemical stored locally or globally is what now forces exchange among different environmental compartments. Deposition of POPs out of the atmosphere and relatively faster degradation within the atmosphere often lead to faster reduction in atmospheric concentrations, which produces a thermodynamic imbalance between soil and air. This imbalance will force a net exchange of POPs from soil to air thus producing a secondary source (Lohmann et al., 2007). Determination of regional and global mass balances of POPs has provided quantitative estimates of the importance of secondary sources to POPs environmental cycling, particularly for the legacy POPs (Nizzetto et al., 2010). Re-emissions of relatively volatile agricultural pesticides (e.g., $\alpha-\mathrm{HCH}$ and $\mathrm{HCB}$ ) and industrial chemicals (e.g., PCBs) accumulated in organic soils and vegetation during high-use periods in the past have now become major environmental factors explaining the response of these chemicals to interannual and longer time-scale $\mathrm{CC}$, characterized primarily by increasing 
temperature anomalies (Ma et al., 2004a, b; Ma and Li, 2005; Gao et al., 2010; Ma and Cao, 2010). The volatilization of many pesticides from either agricultural or background soils presently exceeds dry deposition (including gas absorption and particle deposition), leading to upward fluxes from soil to air (Komprda et al., 2013). On the other hand, the strong association of POPs with OC pools in soils demands that we also consider change in soil biogeochemistry (quality and quantity of OC), which is affected by processes such as loss or gain of plant material, humus accumulation, and loss of soil carbon by metabolism. Each of these processes has the potential to alter the thermodynamic stability of POPs in the surface reservoir (Moeckel et al. 2008, 2009; Teng et al., 2012). Thus, POPs cycling between surface and atmosphere in terrestrial environments is linked both to physical changes (e.g., temperature and moisture) and biogeochemical changes (e.g., carbon cycle) with the latter also providing feedback in the coupling between terrestrial ecosystems and the climate system (Cao and Woodward, 1998a and b; Falkowski et al. 2000; $\mathrm{Xu}$ and Chen 2006; Chen and Xu, 2010;Prentice, 2001; McGuire et al., 2009). The storage and spatial distribution of soil organic carbon, and their susceptibility to change with altered temperature or moisture conditions, magnifies or mitigates the feedback between global change and soil carbon inventory (Karhu et al., 2014). Increasing temperature and moisture and decreasing snow cover can enhance metabolism of soil organic carbon. Terrestrial ecosystem POPs can be altered by soil-air exchange and partitioning processes, also affected by temperature (Cabrerizo et al. 2009, 2011), while soil organic carbon can be altered through fixation and metabolism, which are affected by temperature, moisture and nutrients, changing the storage capacity for POPs (Cabrerizo et al., 2012; Macdonald et al., 2003). For some water soluble POPs such as perfluorooctane 
sulfonate (PFOS), warmer temperatures may increase plant uptake by transpiration, although these changes may be offset by the effects of increased carbon dioxide in carbon cycling that could reduce the activity of plant stomata and reduce plant transpiration. This would in turn affect the uptake and deposition of POPs to terrestrial surfaces, sequestering them and moving them into vegetation-covered soil $\mathrm{C}$ pools (Nizzetto et al. 2008; Teng et al., 2012). Bioavailability of POPs in soils (i.e., a higher proportion may be in the dissolved phase in soil-water system) may increase with the predicted decline in soil organic carbon content (Bellamy et al., 2005). Soil respiration induced by microbe and plant metabolism, which is the second largest terrestrial $\mathrm{C}$ flux from the soil surface to the atmosphere (Bond-Lamberty and Thomson 2010), can affect POPs partition and transformation as well (Teng et al., 2012). However, POPs transfers and partitioning in organic and inorganic soil matrixes at the microscale is, as yet, unclear (Doick et al., 2005) because of the knowledge gaps in the understanding of the response of soil respiration to temperature and soil humidity and how this will affect the capacity of soils for biodegradation of POPs and OC turnover (Semple et al., 2007).

Overall, terrestrial carbon and biogeochemical processes are recognized for their potential importance to POPs mass balances in soils. It is also clear that biogeochemical cycling will change with increasing temperatures, thawing of permafrost, change in soil moisture, and alteration in nutrient supply in terrestrial ecosystems. 
Table 1. Major physicochemical properties of POPs as functions of temperature (T)

\begin{tabular}{ll}
\hline $\begin{array}{l}\text { Physicochemical } \\
\text { property }\end{array}$ & Expressions by temperatures* \\
\hline $\begin{array}{l}\text { Vapour pressure }\left(\mathrm{P}_{\mathrm{A}}\right) \\
\begin{array}{l}\text { Partitioning coefficient } \\
\left(\mathrm{K}_{\mathrm{p}}\right)\end{array}\end{array}$ & $K_{p 1}=K_{p 2}\left(T_{r e f}\right) \exp \left[-\frac{\Delta U_{p}}{R}\left(\frac{1}{T}-\frac{1}{T_{r e f}}\right)\right]$ \\
Henry's law constant $(\mathrm{H})$ & $H=\exp \left[2.303\left(-\frac{a_{h}}{T}+b_{h}\right)\right]$ \\
$\begin{array}{l}\text { Octanol-air partition } \\
\text { coefficient }\left(\mathrm{K}_{\mathrm{OA}}\right)\end{array}$ & $\log K_{O A}=a_{0} / \mathrm{T}-b_{o}$ \\
$\begin{array}{l}\text { First order rate constant } \\
\text { for degradation in air }(\mathrm{k})\end{array}$ & $k=k\left(T_{r e f}\right) \exp \left[\frac{\Delta E}{R}\left(\frac{1}{T}-\frac{1}{T_{r e f}}\right)\right]$ \\
\hline
\end{tabular}

${ }^{*}$ where $\mathrm{T}$ and $\mathrm{T}_{\text {ref }}$ are temperature and reference temperature $\left({ }^{\circ} \mathrm{K}\right) ; \mathrm{m}$ and $\mathrm{b}$ are linear regression coefficients for vapour pressure; $a_{h}$ and $b_{h}$ are linear regression coefficients for Henry's law constant, $\mathrm{a}_{0}$ and $\mathrm{b}_{0}$ are linear regression coefficients for octanol-air partition coefficient; $\Delta E$ is the activation energy $\left(\mathrm{J} \cdot \mathrm{mol}^{-1}\right)$, and R is ideal gas constant.

For freshwater systems, understanding the sources and sinks for POPs in any given lake is essential to assess bioaccumulation in the lakes' food web. Toxic substances have been routinely discharged to the Great Lakes basin through waste sites, river runoff, and atmospheric deposition. During the last century, these pollutants accumulated in large enough quantities to warrant concern regarding the effects on human health and wildlife in the Great Lakes. The adverse effects of POPs on the Great Lakes have instigated efforts to clean up and reduce these chemicals through international agreements (Great Lakes Water Quality Agreement (GLWQA) and the Great Lakes Binational Toxics Strategy (GLBTS)). Mackay et al. (1994) and Gobas et al. (1995) have investigated major pathways of POPs entering and leaving the Great Lakes by developing models that incorporate dry and wet atmospheric deposition, diffusive gas-phase exchange between the air and water (or absorption by lake water and volatilization from lakes), water-sediment exchange, inputs from land-based sources, inflow and outflow from 
interlake rivers, changes in POPs inventories in lake water and sediment, transformations in water and sediment, and burial. All of these pathways have plausible links with CC. Since warming favours POPs partitioning from particle and liquid phase to gas phase, it can be anticipated that under global warming POPs would tend to volatilize from the lakes to the air, especially for legacy POPs whose atmospheric emissions have been terminated and whose life time in the air is much shorter than that in water. Change in air-water exchange will, in turn, alter the balance in water-sediment exchange. Lake sediment, which contains a high organic carbon content, is a major reservoir of POPs. The drawdown of POPs in lake water due to net evasion to the atmosphere then promotes net exchange from the large sediment reservoir back into the water column (Jeremiason et al., 1998). Such feedback may be associated both with changes in the interaction of organic carbon cycling between lake water and sediment, and change in mean temperature, linking POPs fate in fresh water system with global change, including also eutrophication. Figure 2 illustrates long term trend of perturbed water concentrations $\left(\mathrm{C}_{\mathrm{w}}{ }^{\prime}, \mathrm{ng} \mathrm{L} \mathrm{L}^{-1}\right)$ due to air-water exchange and water-sediment exchange of PCB-153 in Lake Ontario of the Great Lakes from 1970 to 2100 using the multi-model ensemble forecasted surface air temperature (SAT) anomalies from the Intergovernmental Panel on Climate Change (IPCC) $20^{\text {th }}$ century $20 \mathrm{C} 3 \mathrm{M}$ and $21^{\text {st }}$ century Special Report on Emissions Scenarios (SRES) - A1B scenarios (Pachauri and Reisinger, 2007). The perturbed concentration is defined as the departure from the mean concentration in a perturbation theory for POPs (Ma and Cao, 2010). In this theory, the concentration of a persistent chemical can be defined by the sum of its mean concentration, $\bar{c}$, plus a perturbation concentration, $c^{\prime}$, produced by changes in temperature and temperature 
anomalies; namely $c=\bar{c}+c^{\prime}$, or $c^{\prime}=c-\bar{c}$ where $\bar{c}$ is averaged over a sufficiently long period of time (preferably decadal or longer period of time). From its definition, $c^{\prime}$ can be either positive or negative and reflects, to some extent, the potential CC signals in the time series of a persistent chemical. Figure 2 shows that the perturbed water concentrations of PCB-153 decline quickly due to the increasing water-air exchange (deep blue line), as a result of increasing temperatures (dashed purple line), which favours liquid to gas phase partitioning. Declining PCB-153 in water then leads to an increasing perturbed water concentration due to enhanced water-sediment exchange (solid red line), which counters the loss of PCB-153 by air-water exchange.

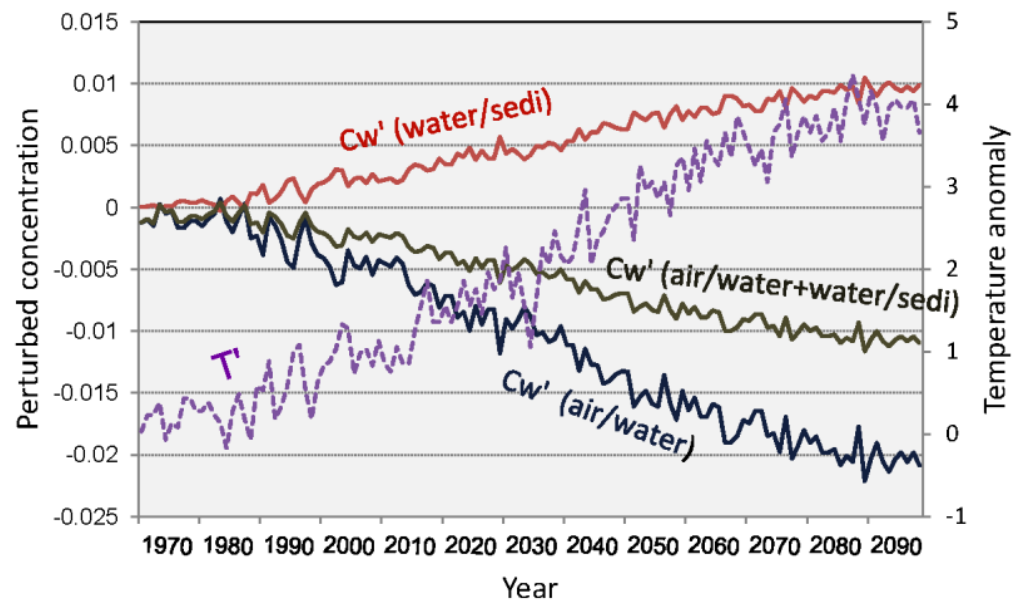

Figure 2. Perturbed water concentrations $\left(\mathrm{C}_{\mathrm{w}}, \mathrm{ng} \mathrm{L}^{-1}\right)$ of $\mathrm{PCB}-153$ due to air-water exchange (air/water, solid deep blue line), water-sediment (water/sedi, solid red line), summed perturbed water concentrations (air-water exchange + water-sediment exchange, solid deep brown line), and SAT anomalies (K) from 1970 to 2100 (blue dashed line). $\mathrm{C}_{\mathrm{w}}{ }^{\prime}$ is scaled on the left-hand-side $\mathrm{Y}$ axis and $\mathrm{T}^{\prime}$ is scaled on the right-hand-side $\mathrm{Y}$ axis. For details of perturbation model, readers are referred to Ma and Cao (2010), Ma et al., (2011), and Zhao et al. (2015).

\subsection{Atmosphere}

The atmosphere is an important transport route for POPs. How far in the atmosphere a chemical can travel depends on its persistence and degree of mobility (Bennett et al., 1999), the latter of which is affected by many meteorological variables including 
especially temperature, precipitation and particulates. Air concentrations and transport properties are two major factors contributing to the regional and global distribution of these toxic chemicals. Long-range atmospheric transport (LRAT) patterns of POPs are complex due to rapid and often highly variable changes in meteorology, but transport follows certain rules defined by the physics of atmospheric circulation and the physical-chemical properties of the chemicals. Although LRAT of POPs may be difficult to predict over short periods of time (days, weeks), the climatic statistics of transporting events (frequency, intensity) can be used to provide a more robust estimate of LRAT on seasonal, annual, and longer time scales. This is because episodic transport events appearing to occur randomly may, nevertheless, exhibit stable long-term mean states and general statistical properties (e.g., standard deviation, extremes). For example, northward episodic atmospheric transport routes of POPs from the southern US to Canada have been shown to coincide with west-northwest storm tracks approaching from the US (Ma et al., 2005; Yao et al., 2007). Trans-Pacific transport of POPs also follows west to east storm tracks across the North Pacific Ocean (Bailey et al., 2000; Zhang et al., 2008). These storm tracks are climatological winds that repeatedly occur, but may change in position and strength with climate variability. Using atmospheric concentration data for the North American Great Lakes region, Ma et al. (2004a, b) sought relationships between POPs concentration time series and sources of interannual climate variability, notably the El Niño-Southern Oscillation (ENSO), North Atlantic Oscillation (NAO), and tropical Pacific sea surface temperature anomalies (SSTA) (Ma et al., 2004a, b; Ma and Li, 2006). The data show that during positive phases of the NAO, stronger than normal westerly winds over POPs source regions in the Canadian Prairies coincide with enhanced POPs 
air concentrations in the downwind Great Lakes region. Likewise, increase in the eastern tropical Pacific sea surface temperature (SST) correlated positively with increasing POPs air concentrations over the Great Lakes. Poleward atmospheric transport of POPs is also influenced by climate change (Hansen, et al., 2015; Friedman et al., 2014; Friedman and Selin, 2016). Signatures of atmospheric circulation teleconnection patterns, mostly on an interannual scale, have been detected in atmospheric concentrations of $\mathrm{HCHs}$, chlordanes, and PCBs measured at Alert, Nunavut, a high Arctic site in Canada, and at Zeppelin Mountain, an Arctic monitoring site of POPs operated by Norwegian Institute for Air Research (NILU). The three most important atmospheric circulation modes, the ENSO, NAO, and Arctic Oscillation (AO), have also been linked to the changes in atmospheric POPs concentrations in the Arctic (Ma et al., 2004a; Macdonald et al., 2005; Hung et al., 2005; Becker et al., 2008). Anomalies in these atmospheric circulation modes indicate changes in the intensity and position of major meridional wind streams in the Northern Hemispheric atmosphere, which enhance pole-ward atmospheric transport depending on phase. Detection of an association between deposition of POPs and climate change (as manifested by changes in air temperature and precipitation on decadal or longer time-scales) is subject to large uncertainties. These uncertainties are due primarily to: (1) short and sparse air measurement data of POPs across the globe, which are not long enough to discriminate CC signatures that contain decadal scale variability; (2) Changes in magnitude and direction of large-scale winds as a consequence of CC are more difficult to assess because such changes are not readily measurable (UNEP/AMAP, 2010), and; (3) There are very limited measurements of POPs in multi-media compartments (ocean, soil, ice/snow, permafrost), which makes it difficult to assess exchange of POPs 
between atmosphere and these compartments, and the spatial distribution of POPs globally. To address these difficulties, numerical models, as elaborated in Section 4, have been used to examine the influence of long-term climate change on global distribution and levels of POPs under projected CC and emission scenarios in the $21^{\text {st }}$ century (MacLeod et al., 2005; Lamon et al., 2009; Ma and Cao, 2010; Wöhrnschimmel et al., 2013; Friedman et al., 2013; Octaviani et al., 2015).

Friedman et al. (2014) conducted a numerical assessment to show that the effect of $\mathrm{CC}$ on polycyclic aromatic hydrocarbons (PAHs) transport into and out of the Arctic via the atmosphere was insignificant. Due to the temperature dependence of physicochemical properties (Table 1), alterations in air temperatures induced by CC may play a more significant role in the LRAT of POPs compared to winds. This is demonstrated by the stronger response of volatile chemicals to $\mathrm{CC}$, manifested by air concentrations that respond to increasing temperature, which promotes volatilization from surface reservoirs to air, and speeds up degradation. Persistence and mobility of persistent chemicals in mobile environmental compartments (air, ocean) are often expressed as the long-range transport (LRT) potential (Bennett et al., 1999, 2001; Scheringer, 1997, 2001;

Müller-Herold et al., 1997; van Pul et al., 1998; Beyer et al., 2000, 2003), which may be formulated by a characteristic travel distance (CTD) as a function of speed (wind, current) and physicochemical properties of POPs (e.g., $\mathrm{K}_{\mathrm{OA}}$, Henry's law constant, and the rates of degradation in a given environmental medium, see Table 1). Given relationships between physicochemical properties and $\mathrm{T}$, the effect of CC on CTDs of POPs may be estimated from projected or actual temperature increases. Figure 3 illustrates the change in CTDs in air at the $3500 \mathrm{~m}$ height for 6 PCB congeners (from PCB-28 to PCB-180) 
between 2000 and 2100 using mean T averaged over the Northern Hemisphere (NH) as projected by the IPCC SRES-A1B emission scenario, estimated using 2D CanMETOP model [The Canadian Model for Environmental Transport of Organochlorine Pesticides, (Ma, 2010)]. CTD is defined as the product of wind speed and an overall instantaneous characteristic time (Bennett et al., 1999). A constant mean wind speed has been used here because the projected average annual wind speed changes little over this time period. Among these congeners, the more volatile PCB-28 and -52 are primarily in the gas phase and therefore have higher CTDs, but all 6 PCB congeners show the increase in CTDs with the projected increase in temperature towards the end of the $21^{\text {st }}$ century.

Depending on their physicochemical properties, POPs transport in the atmosphere as gases or bound to aerosol particles, with the latter more subject to deposition and washout with precipitation. PCBs, PAHs and PCDDs/PCDFs have high retention to carbon particles (black carbon or soot), which might be transported long distances as fine aerosols (Pekar et al., 1999). Friedman et al. (2014) evaluated the influence of secondary organic aerosols (SOA) and black carbon (BC) on the LRAT of PAHs by examining physicochemical characteristics of various aerosol types and gas-particle partitioning. Their model simulations, which evaluated a range of conditions, showed that PAHs trapped in $\mathrm{BC}$ upon emission yielded best agreement with observed PAHs concentration data. $\mathrm{BC}$, which is frequently rich in $\mathrm{PAH}$, is a short-lived atmospheric climate forcer. The deposition of $\mathrm{BC}$ onto ice and snow darkens the surface, leading to warming of the lower atmosphere and melting of snow and ice (Flanner et al., 2007), which then clearly has the potential to alter the LRAT, air-surface exchange of PAHs carried by the BC, and subsequent movement when snow or ice melts. 
Precipitation and clouds play critical roles in global climate change through either climate forcing or feedback. Given that, generally, the fractional cloud cover increases towards the Arctic (Ma, 2010, Ma et al., 2013, Mao et al., 2014), we may project that increased partitioning and absorption of hydrophilic POPs will take place as clouds transport northward to the Arctic. The understanding of the interaction between clouds and POPs is not yet sufficient to predict to what extent change in fraction of cloud cover due to sea-ice melting associated with $\mathrm{CC}$ would alter POPs environmental cycling in the Arctic. Current modeling exercises suggest that CC-associated precipitation would not alter the environmental fate of POPs significantly compared with temperature-mediated changes (Gouin et al., 2013).

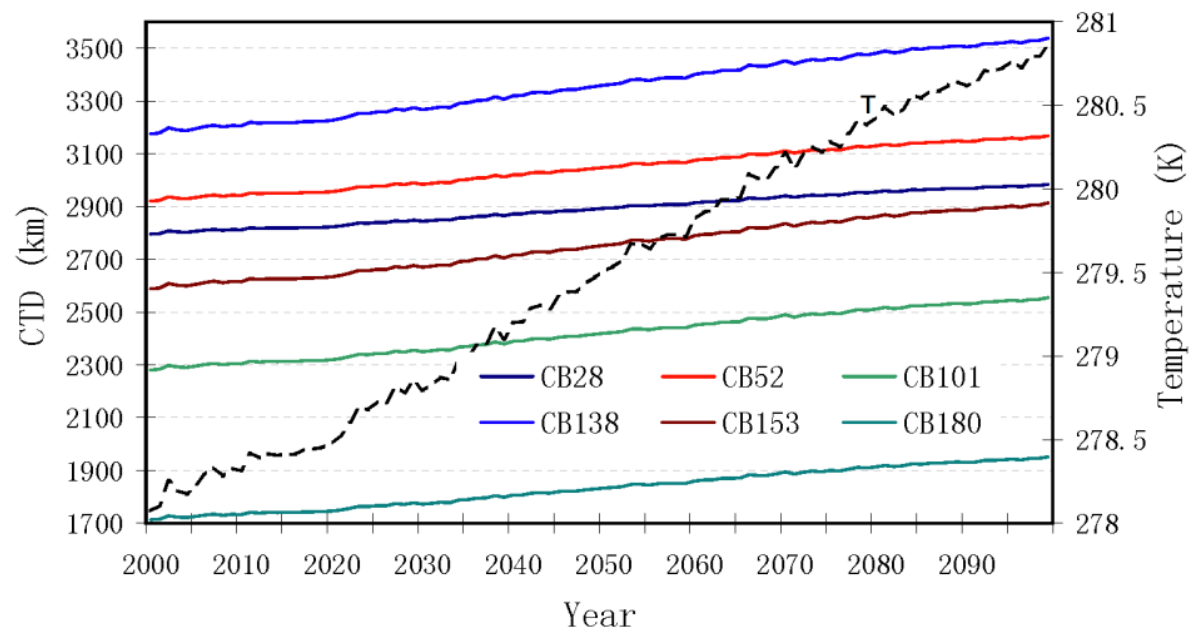

Figure 3. Characteristic travel distance $(\mathrm{CTD}=$ wind speed $\times$ overall instantaneous characteristic time, Bennett et al., 1999) in air for 6 PCB congeners (from PCB-28 to PCB-180) between 2000 and 2100 using mean temperatures averaged over the NH as projected by the IPCC SRES-A1B emission scenario and a constant mean wind speed $\left(\sim 14 \mathrm{~m} \mathrm{~s}^{-1}\right)$ at $3500 \mathrm{~m}$ height, estimated using 2D CanMETOP model (Ma., 2010)

2.4 Marine environment 
The oceans differ significantly from the atmosphere in their response to climate change and how that response might affect POPs cycling. First, the transport rates in the ocean are far slower: ocean currents are typically in the $0-25 \mathrm{~cm} \mathrm{~s}^{-1}$ range compared to winds, which are typically in the $0-10 \mathrm{~m} \mathrm{~s}^{-1}$ range. The Fukushima accident in 2011 provides an exceptionally clear example of the contrast in rates of transport: the atmospheric radioactive signal $\left({ }^{137} \mathrm{Cs}\right.$ and other nuclides) from Fukushima was detected in Europe within 7 days (Masson et al., 2011) and likely reached the North American coast within a couple of days (Stohl et al., 2012). In contrast, the ${ }^{137} \mathrm{Cs}$ tracer signal in the ocean took a little over two years to reach the Canadian continental shelf in the Pacific Ocean (Smith et al., 2015). An important consequence, therefore, of the slow transport by ocean currents is that climate-mediated changes in processes (e.g., degradation, photolysis, sedimentation) have a much longer time to operate over comparable transport distances within the two media. Second, the ocean has an important carbon cycle that includes primary production, a food web, organic carbon metabolism, a large organic carbon reservoir and vertical flux of particulate matter within the ocean. The carbon reservoir is especially important for POPs because many of the compounds are hydrophobic and tend to partition strongly onto organic carbon-rich particles and into lipids. This then leads directly to bio-uptake, bioaccumulation and biomagnification in marine foodweb creating, in some cases, surprising exposures in top predators (Macdonald et al., 2005). Third, with respect to polar oceans, seawater can freeze producing a solid, floating cover. Sea ice, which has many internal processes that affect POPs cycles (e.g., Pućko et al., 2011; 2013a; 2015), also may directly affect air-sea exchange, dry and wet deposition, distribution of solar radiation, and biological habitat 
and foraging. Fourth, warming of terrestrial environments leads to melting of glacial ice which produces sea-level rise (SLR); we have already seen a global mean SLR of about $0.2 \mathrm{~m}$ since 1900 and a further rise by as much as $1 \mathrm{~m}$ as projected by the end of the century (IPCC, 2013). Sea level rise together with increasing frequency or intensity of storm surges would enhance erosion of contaminated soils in urban and industrial areas, thereby transferring legacy POPs to coastal oceans. Secondarily, the loss of perennial snow and glacial mass would also release POPs archived during earlier periods of high use.

There are also features of global change common to both atmosphere and ocean. For example, both fluid media of air and ocean are becoming loaded with anthropogenic $\mathrm{CO}_{2}$ (IPCC, 2005; 2013). In the case of the ocean, the $\mathrm{CO}_{2}$ leads to acidification, which has important consequences for inorganic equilibria within the ocean and for biological populations (RSC, 2005; AMAP (The Arctic Monitoring and Assessment Programme), 2013), which may then interact with organic carbon and POPs pathways. Virtually nothing is known about potential interactions between POPs and acidification, either directly or indirectly, but it seems likely that the largest effects would accompany changes in foodweb structure caused by acidification. The atmosphere and oceans are both warming (IPCC, 2005; 2013). The heat capacity of the ocean is far larger than that of the atmosphere such that the modest rate of heat increase in the upper ocean

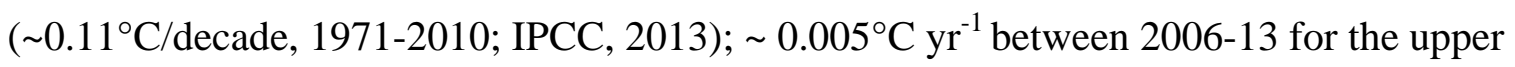
$500 \mathrm{~m}, \sim 0.002^{\circ} \mathrm{C}$ below this down to $2000 \mathrm{~m}$ (Roemmich et al., 2015) dominates the energy imbalance in the climate system. Chemical kinetics would predict that this small rate of warming of the upper ocean will generally lead to more rapid degradation and 
evasion of POPs, but the increase would be hardly detectable. However, as noted above, the cryosphere is special in its response to warming due to the possibility of phase change between solid and liquid. In particular, the Arctic Ocean has witnessed a remarkable loss of summer sea ice cover, especially in the western (Pacific) regions (e.g., Stroeve et al., 2012; Wood et al., 2015). Ice buffers surface water temperatures, maintaining them near the freezing point of water. Melting of ice contributes to surface stratification, which prevents mixing, and loss of ice cover permits solar radiation to be absorbed into the low-albedo surface layer where it goes entirely to heating. Although solar radiation is the dominant source of heat to the surface mixed layer, advected heat in water entering from the Pacific and Atlantic Oceans has also increased during the past two decades (Carmack et al., 2015). The oceans initially obtain their POPs through atmospheric transport followed by dry and wet (snow and rain) deposition, diffusive gas exchange between air and surface ocean, and riverine input (Gioia et al., 2008). During the initial period of POPs usage, when emissions and air concentrations were increasing, the ocean lagged the atmosphere in contamination such that net deposition was from air to surface waters. Once the use of a particular POP was restricted or banned, atmospheric levels began to decline, and when these dropped below a certain threshold, net exchange reversed and the reservoir of the contaminant accumulated in the surface ocean then became a source back into the atmosphere. The first environmental evidence of this reversal of exchange was demonstrated for $\mathrm{HCH}$ (Jantunen and Bidleman, 1995). The continuing importance of the surface ocean reservoir as a secondary source of POPs contamination to the atmosphere has long been followed with interest (Li et al., 2004; Jantunen et al., 2008; Bidleman et al., 2007; Shen et al., 2004; Wong et al., 2010), with a recent paper suggesting that 
eventually the various degradation processes in the water will remove the bulk of the HCH from its last reservoir - the Arctic Ocean - by about 2040 (Pućko et al., 2013a). Although the Arctic Ocean is special due to loss of ice cover and subsequent warming, the reversal witnessed there has likely also taken place elsewhere and for other compounds like DDT and in other oceans, such as the South Pacific (Stemmler and Lammel, 2009; Zhang and Lohmann, 2010; Wong et al., 2010). On the other hand, measured PCBs data in air and water across the Atlantic and Arctic in 2004 showed that, on average, deposition still dominated over volatilization for PCBs in the Arctic region (Gioia et al., 2008). Nevertheless, the important point to be made here is that once primary sources are removed, the secondary sources to the atmosphere begin to dominate, and emissions from these secondary sources are strongly affected by environmental conditions, which are subject to climate change and variability (e.g., Wang et al., 2010).

The fate and cycling of POPs within the oceans also depend on a number of time-dependent chemical, physical, and biological processes, which again emphasizes the importance of the transport time set against the residence time of a POP within the surface ocean. Arguably the most important processes affecting the dynamics of POPs in the ocean are associated directly or indirectly with the carbon cycle. The hydrophobicity of POPs can be represented by $\mathrm{K}_{\mathrm{OW}}$, which for most POPs ranges from $10^{4}$ to $10^{8}$, suggesting that the concentration of POPs in organic matter is 4-8 orders of magnitude higher than in seawater. Hence, most of the POPs become strongly associated with the various organic pools (dissolved, colloidal, particulate) in the water column. Accordingly, organic carbon pathways end up becoming the dominant pathways for POPs, especially when the toxic effects of these chemicals are under consideration. What makes it so 
challenging to project the effects of climate change on POPs in the oceans, are the numerous possibilities for bifurcations in pathway (e.g., primary production to pelagic, benthic or ice foodwebs, foraging patterns, vertical flux or migration to deep ocean), and for POPs concentrating processes (e.g., partitioning, biomagnification, respiration) (Macdonald et al., 2002). Climate change can operate on both the bifurcations and on the concentrating processes, thus producing a collateral effect on the POPs pathway.

While the potential significance of CC for POPs cycling in marine environments has been highlighted in several review articles (e.g., Macdonald et al., 2005; Schiedek et al., 2007; Noyes et al., 2009; Noyes and Lima, 2015; Kallenborn et al., 2012; UNEP/AMAP expert group, 2011; O’Driscoll et al., 2014; Teran et al., 2012; Rockstrom et al., 2009; Schindler and Smol, 2006), there have been no extensive field investigations in the marine environment designed to produce a quantitative understanding of the effect of CC on POPs. Among the processes highlighted above, air-water exchange probably enjoys the strongest basis to forge linkages because there are a number of reasonably long time series for atmospheric POPs concentrations. In the cryosphere, air-water exchange is also facilitated by decreasing sea ice cover, which permits atmospheric deposition to occur directly on the water surface and enhances the rate of progress toward equilibration between air and water no matter which direction the net exchange favours (e.g., see Ma et al., 2011). The aquatic carbon cycle, which begins with the production of phytoplankton biomass, also plays the important role in influencing the net air-water exchange by controlling the dissolved water concentration. Uptake of POPs by phytoplankton and zooplankton occurs rapidly in the upper ocean (e.g., Pućko et al., 2013b). These lower trophic levels then support a vertical flux of organic matter out of the ocean's surface 
mixed layer (Hwang et al., 2015; Bishop, 1989). Given the strong partitioning of many contaminants to organic matter, the process of vertical flux 'draws down' dissolved POPs concentrations in the surface layer much in the same way it draws down $\mathrm{CO}_{2}$ and, likewise, forces net exchange of POPs from atmosphere to ocean to re-attain equilibration (Dachs et al., 1999). The process of transfer out of the upper ocean can be passive in the form of biological and inorganic detritus (e.g., Timothy et al., 2013), or larger dead animals (Bidleman et al., 2013), or the vertical migration of living zooplankton (Pućko et al. 2013b). The general process of removing biological matter (C, N, P, Si) from the upper ocean in this way is termed the "biological pump". In proportion to how strongly any particular contaminant associates with $\mathrm{C}$ and lipids, or absorbs onto particulate surfaces (that is, exhibits Redfield behaviour), the biological pump then becomes also a contaminant pump (Dachs et al., 2002; Nizzetto et al., 2012; Åkerblom et al., 2015). Using a coupled global 3-D model of oceanic mercury $(\mathrm{Hg})$ and plankton dynamics and carbon respiration, Zhang et al. (2015) assessed riverine input of $\mathrm{Hg}$ to global oceans. Their results confirmed that atmospherically deposited $\mathrm{Hg}$ to the open ocean in the middle and lower latitudes was more accessible for biological uptake than the input from rivers. What is of exceptional interest with respect to $\mathrm{CC}$ is that that biological pump may be strongly affected by climate variability and change, driven either by light or nutrient supply. Evidence has been provided not only for shifts in phytoplankton productivity (e.g., Henson et al., 2010; Arrigo et al., 2015; Lowry et al., 2014; Palmer et al., 2014) but also for significant change in vertical flux (Boetius et al. 2013).

The measurement of dissolved or particulate POPs in ocean waters, particularly in deep waters, is exceptionally sparse. There is therefore practically no basis to evaluate the 
effects of CC on POPs in the ocean before they enter the food web. Since it is relatively simple to measure, $\mathrm{HCH}$ has accumulated a much better marine data base from which budgets have been determined (Macdonald et al., 2000), and we now understand what controls its vertical and horizontal distributions in the ocean (Li et al., 2002; Pućko et al., 2012a, b). However, even for $\mathrm{HCH}$ the time-series data have proven sufficient only to validate time stepped box models at a few points (e.g., Li et al., 2004).

\subsection{Cryospheric environment}

The cryosphere is a large component of the climate system that is particularly sensitive to global warming due to the feedback inherent in altering reflective surfaces (snow, ice) to energy-absorbing surfaces (soil, water, vegetation), and due to the alteration in biogeochemical systems as a consequence of converting ice to water. A recent article has reviewed many aspects of POPs in the cryosphere and discussed potential associations with CC (Grannas et al., 2013). Within the cryosphere POPs tend to break down more slowly and are subject to a number of magnifying processes, some of which are unique to cold environments (Macdonald et al., 2002). A surprising finding during the 1960s was widespread enrichment of some POPs in animals living in the Arctic, a region where these chemicals were never produced and almost never used. In particular, top predators in marine ecosystems were particularly vulnerable due partly to favorable transport and deposition of POPs to cold regions (Section 2.3) followed by strong biomagnification in fat-dominated food webs. Due to the relatively lower temperatures, there is a general thermodynamic forcing that favours a net transfer of POPs from temperate industrial and agricultural regions to cold regions like the poles and high mountains. Furthermore, these 
regions have mechanisms that favour deposition to surfaces due to stronger partitioning onto particulates and snow, and/or stronger partitioning into cold water (Macdonald et al., 2005; Ma et al., 2011). Although the annual precipitation in the Arctic is relatively low (less than $500 \mathrm{~mm}$ ), much of the precipitation comes in the form of snow, and snow prevails in winter and spring when global wind fields favour rapid air transport of POPs-bearing air from temperate regions into the Arctic (Heintzenberg, 1989). These are the first links in the chain that places industrial and agricultural POP into Arctic foodwebs. It has long been recognized that, given its greater sorption capability, snow is a very efficient scavenger of organic vapours (Goss, 1997; Wania et al., 1998, 1999; Hanot and Donime,1999; Domine et al., 2002; Cabanes et al., 2003). Due to its strong potential for scavenging vapour and particle-bound POPs, and transporting these toward the surface, snow notably influences the transport dynamics of POPs in the NH. Once snow has deposited, processes within the snow become crucial to the subsequent pathway, be it back into the air, or onward into melt water (e.g., Wania, 1997). Declines in the extent of snow cover as part of the changing polar climate (e.g., Comiso et al., 2014; Derksen and Brown, 2012; Callaghan et al., 2011) will, therefore, affect the fate of POPs in polar and alpine regions (Macdonald et al., 2003, Stocker et al., 2007). Vapour scavenging, a function of the air temperature and the specific surface area (SSA) of the snow, is predicted to be most pronounced for snow possessing high SSA (e.g. $\left.1 \mathrm{~m}^{2} / \mathrm{g}\right)$ and at cold temperature $\left(<-10^{\circ} \mathrm{C}\right)$, resulting in scavenging ratios for semi-volatile chemicals being generally higher than rain (by over an order of magnitude) (Lei and Wania, 2004). The seasonal snowpack therefore serves as a temporary repository for chemicals transported to higher altitudes/latitudes; high concentrations have been widely reported for a number 
of different POPs in both mountain and arctic snow (e.g., Blais et al., 2001, Herbert et al., 2006; Arellano et al., 2011; Enge et al., 1998).

The sorption of organic chemicals onto water droplets and ice surfaces has also been investigated (Goss, 1997; Donaldson and Anderson, 1999; Roth et al., 2002, 2004). Using equilibrium partitioning calculations, Lei and Wania (2004) compared the capacities of rain and snow to scavenge gaseous and particle-bound organic chemicals (HCHs, PAHs, PCBs etc.) under cold and warm atmospheric conditions. Their results demonstrated that partitioning of semi-volatile organic chemicals from the vapour phase to liquid water droplets, atmospheric particles and snow surfaces is favoured by lower air temperatures, which then increases the importance of snow and ice melt water as reservoirs of POPs (Finizio et al., 2006; Villa et al., 2006; Grynkiewicz et al., 2001, 2002). Ocean transport also plays a significant role to deliver some contaminants to polar region (Section 2.4), particularly for compounds that partition strongly into cold water like $\mathrm{HCHs}$. In particular, the exceptionally strong partitioning of $\beta-\mathrm{HCH}$ into water diverts its pathway from atmospheric winds to predominantly surface ocean currents on the way from sources in Asia to the Arctic Ocean (Li et al., 2002). The processes of particulate scavenging and air-water partitioning offer non-linear mechanisms to switch between transporting mechanisms that are very sensitive to temperature. As pointed out by Wania (2003), the favourable scavenging and deposition of chemicals into cold environments is a 'Goldilocks' problem. Very strong scavenging may limit the potential for a chemical to make it to the Arctic via the atmosphere (e.g., $\beta$-HCH), slightly weaker scavenging permits the chemical to arrive in the Arctic where the colder temperatures then favour its trapping (e.g., $\alpha-\mathrm{HCH}$ ), whereas very weak scavenging would permit the 
chemical to pass through the Arctic in the atmosphere without depositing (e.g., chlorofluorocarbons CFCs). It is therefore the case that the temperature-sensitive partitioning processes, which are obviously affected by global warming and other changes associated with scavenging (rain, snow), provide variable conditions that sort contaminants into environmental reservoirs and transporting systems, which then alter capacities of the various reservoirs, the rates of transport (discussed above) and the sink strength (Macdonald, 2007). For many POPs, the cold, dark regions beneath perennial sea ice, together with very low vertical particle flux (e.g., Honjo et al., 2010; Hwang et al., 2015), permits chemicals like $\mathrm{HCH}$ to persist long enough in near-surface waters to transport over decadal time periods to even the most remote locations (Macdonald et al., 2000). The small vertical particle flux and the occasional sinking of larger organisms do, however, permit further transport into basin waters and sediments for chemicals that partition strongly into organic particles or become concentrated in foodwebs (e.g., Sober and Gustafson, 2014; Bidleman et al., 2013) .

The Arctic is warming at a rate of almost twice the global average. Perhaps the most visible change to the globe in recent decades has been the rapid decline of arctic sea ice cover toward the end of summer (Steele et al., 2008; Stroeve et al., 2012) and the loss of snow cover (Derksen and Brown, 2012). The Antarctic has also received contaminants through LRT (e.g.,Cabrerizo et al., 2012; Corsolini et al., 2007; Bengtson Nash, 2011). However, since most POPs have been produced and used in the NH, the Arctic has received a greater input of contaminants and hence experienced greater exposures to biotic and abiotic environments (Figure 1). The fact that human populations live within the Arctic has also underscored the risks there from POPs exposures especially for 
circumpolar countries. It is worth noting that, despite the remoteness of Antarctica, POPs have also been detected in this region as early as the 1960s; arriving primarily via atmospheric LRT from the emission sources in the Southern Hemisphere ( $\mathrm{SH})$, as the exchange of air masses within hemispheres occur faster than between hemispheres. Given that the Antarctic is also undergoing rapid changes which could impact both chemical behavior and ecosystem function, $\mathrm{CC}$ in the Antarctic and the $\mathrm{SH}$ is expected to alter the cycling and bioavailability of POPs in the southern polar region (Bengtson Nash, 2011). Although ambient POPs data and corresponding assessments in the Antarctic are extremely scarce, it is expected that knowledge about interactions between $\mathrm{CC}$ and arctic environments is also applicable to the endemic ecosystem in the Antaractic.

A direct, readily observable impact of $\mathrm{CC}$ on POPs cycling in the Arctic is mediated through snow/ice melting, which releases contaminants deposited during earlier, high-use decades, allowing them to re-enter the air (Meyer and Wania, 2008). This remobilization from these old, archived reservoirs may temporarily reverse, or stall, declining trends in the atmosphere due to emission controls (Zhao et al., 2015). Reduced sea ice extent permits greater warming of the surface Arctic Ocean through the absorption of solar radiation [the so-called albedo feedback (Calaghan et al., 2011)] . In addition, more open water across the Arctic will alter pressure fields potentially leading to more unstable climatic conditions, extreme weather (e.g., Serreze et al., 2000) and increase in cloud cover (Overpeck et al., 2005), as well as alteration in the balance of snow and rain; each of which has the potential to affect POPs pathways as discussed above.

Arctic sea ice, permanent ice and glaciers undergo ablation under arctic warming. As reservoirs of previously deposited POPs, increased melting of perennial snow cover and 
permanent ice would release POPs to air and water (Bogdal et al., 2010; Blais et al., 2001). For example, Jantunen et al. (2008) reported that an abrupt increase in $\alpha-\mathrm{HCH}$ concentration in air during 1999 accompanied ice breakup in the central Archipelago. Increasing in air concentrations of PCB-52 and 101 observed at Stórhöfði, a coastal site on Iceland, could also have been brought on by sea ice retreat and deglaciation of the retreating ice caps of Mýrdalsjökull and Eyjafjallajökull in close proximity to this site (Hung et al., 2016; AMAP, 2013). Melting snow and ice may also release POPs directly into sea water (Gieisz et al., 2008). For all of these complex interactions between glaciers, snow, ice cover, ocean and atmosphere, the only way to understand consequences to POPs distributions would be to collect coherent time series, something that is scarce for every medium except, perhaps, the atmosphere. A recent series of studies has shown that sea-ice brines provide mechanisms to increase POPs concentrations relative to sea ice and to deliver them efficiently to lower trophic levels in the food chain (phytoplankton, zooplankton) (Pućko et al., 2010a,b; 2011; 2012a, b; 2013b; 2015). The importance of ice-brine and the age of the ice for the accumulation of POPs and their fate in the Arctic has also been noted by the ArcRisk program (http://project.arcrisk.eu/). The major point here with respect to recent change in the Arctic is that the conversion of much of the perennial ice pack to seasonal ice (e.g.,Wood et al., 2015), which is projected to continue until the entire Arctic becomes seasonally ice covered, also changes the coupling between POPs deposited on the ice and the food web (Pućko et al., 2015).

There are many important changes going on in the Arctic other than the loss of perennial ice, which include freshwater balance, the organic carbon cycle and acidification (Macdonald et al., 2015). Among these changes, ones that affect primary 
production (e.g., upwelling and mixing), connections between ice, water, sediment, foodwebs, and the vertical flux of organic matter will clearly be important for their collateral effects on POPs pathways as discussed in section 2.4. Despite the importance of changes in these processes (ongoing and projected), and the potential for collateral changes to POPs pathways, this topic remains almost entirely speculative.

Galbán-Malagón et al. (2012) have shown that PCBs in transport to the Arctic Ocean are intercepted along the way by sequestration into the oceanic biological pump. Increases or decreases in the biological pump mediated by changes in ice climate or nutrient supply, therefore, can affect the fraction of POPs that make it into the Arctic Ocean, and the air-sea exchange rate along the pathway (e.g., Dachs et al., 2002).

\section{Searching for climate change signals in POPs monitoring data}

There are presently three approaches that have been used to look for connections between $\mathrm{CC}$ and POPs:

1) Statistical methods that examine correlations between climate indicators (e.g., NAO, ENSO, AO) and POPs time series. These methods face the enormous difficulty of detecting trends or cycles set against noisy backgrounds. Power of such approaches can only be increased by longer time series and more monitoring points;

2) Coupled numerical computer models that may include representations of a few, or many, of the important processes such as transport, partitioning, degradation, concentration, biogeochemical cycling, food-web transfers etc.. These models then may explore the effect of future climate scenarios developed, for example, by the IPCC;

3) Statistical inference based on comparison between observation and model simulated signals. 
Atmospheric POPs monitoring data arguably provide the best opportunities for detecting the effects of climate, partly because they contain reliable data for a suite of compounds together with climate variables (e.g., temperatures, pressures, winds), and partly because some atmospheric time series have been collected long enough to incorporate decadal-scale variability. For instance, Canada and the US have collaborated in the assessment of atmospheric loadings of toxic contaminants over the Great Lakes since 1990 (Hoff et al., 1996; Cortes et al., 1998) and Europe and Canada have maintained long-term atmospheric monitoring programs at research stations in the Arctic (AMAP, 2013; Kallenborn et al., 2012; Hung et al., 2005). Using the Great Lakes POPs dataset sampled for 24 h every 12 days (1991 - 2003), Ma et al. (2003) provided perhaps the first field evidence linking interannual climate variation with POPs concentrations in the atmosphere. Specifically, they found strong correlations between the seasonally-averaged atmospheric concentrations of HCB and the Multivariate ENSO Index (MEI) for winter (December-February) and spring (March-May). These correlations were stronger in the western upper Great Lakes than in the eastern portion of the Great Lakes, and corresponded well to the spatial variability of the surface air temperature in North America during El Ninõ years. Subsequent studies extended the associations between POPs and other dominant indicators of interannual climate variation in the NH, including the NAO, the Pacific North American (PNA) anomaly, and SSTA (Ma et al., 2004a; Ma and Li, 2006; Gao et al., 2010). Using a multivariate regression model, $\mathrm{Ma}$ and $\mathrm{Li}$ (2006) showed that annual global reemission of $\alpha-\mathrm{HCH}$ from secondary sources, its atmospheric half-life, and indices for the spring NAO and ENSO could explain $78 \%$ of spring mean air concentration variance in the 1990s over the Great 
Lakes. They attributed the strong interannual variability of atmospheric concentrations of selected POPs to reemission from terrestrial surface reservoirs (e.g., soils, vegetation, lakes), accumulated from past usage, forced by increasing temperatures associated with the atmospheric teleconnection patterns. Using extended time series of measured POPs air concentrations over the Great Lakes region from 1992 to 2007, Gao et al. (2010) revisited relationships between seasonal mean air concentration of organochlorine pesticides and major climate variables in the $\mathrm{NH}$. To increase the power to extract cyclical climate signals from the air-concentration time series, Gao et al. (2010) first removed linear trends, which were likely driven predominantly by degradation processes as manifested by atmospheric half-lives in the post-emission era. The detrended time series correlated more strongly with the ENSO and NAO, and reflected the interdecadal variation of the NAO index, which has been increasing since the mid-1990s, probably in response to global warming (Hoerling et al., 2001).

Macdonald et al. (2005) have noted potential influence of the AO on the environmental fate of POPs in the Arctic through significant changes in large-scale wind and temperature fields in the Arctic and the $\mathrm{NH}$ forced by the Northern-hemisphere Annular Mode (NAM) of climate system (Wallace and Thompson, 2002). Eckhardt et al. (2007) assessed numerically the association of the poleward atmospheric transport of air pollutants with dominant atmospheric circulation teleconnection patterns. They concluded that the NAO exerts a strong control on the pollution transport into the Arctic, particularly in winter and spring. Positive phase of the NAO favoured atmospheric transport of air pollutants, like CO, emitted from Europe to the Arctic. However, their modeling study did not include POPs. Becker et al. (2008) compared seasonal and 
long-term trends of $\alpha$ - and $\gamma-\mathrm{HCH}$ air concentrations, collected at two arctic stations (Zeppelin and Alert) with the AO Index. They found a correlation between AO fluctuation and $\alpha-\mathrm{HCH}$ at Zeppelin (Svalbard, Norway), but not at Alert (Ellesmere Island, Canada). Further examination of the records showed that a much larger air concentration difference occurred between summer and winter months when the AO was in the negative phase during the 2000s. During positive AO years in the 1990s, the concentration difference between summer and winter was much less pronounced. Composite analysis of the influence of AO, NAO and ENSO on pole-ward atmospheric transport (NCP, 2013) showed warmer conditions from mid to high latitudes in the NH during the positive phase of NAO and AO. Strong warming in the Arctic is also associated with the positive NAO. Stronger than normal southerly winds dominate relatively higher latitudes extending from $45^{\circ} \mathrm{N}$ to the Arctic. This wind pattern is particularly favorable for pole-ward LRAT from Eurasia where major emission sources of POPs lie mostly north of $40^{\circ} \mathrm{N}$ (e.g, Breivik et al., 2007).

To discern decadal or longer variability in climate cycles (e.g., global warming), a time-series must be longer than 30 years [the classical climate change period (Le Treut et al., 2007)]. This questions the capacity to extract decadal-scale climate signals in, for example, atmospheric POPs data from currently available observational datasets, which extend to about 20 years. Given that the Arctic is warming at a rate of almost twice the global average, which has resulted in extensive sea ice melt toward the end of summer since the 2000s (Steele et al., 2008), the POPs atmospheric time series in the Arctic might provide best-available datasets to detect the influence of climate change and variability on the environmental cycling of POPs. Overall, long-term trends of POPs atmospheric 
concentrations have tended to decrease (Hung et al., 2010, 2016; Ma et al., 2011; Kong et al., 2014). However, during the 2000s the declines for many of the toxic chemicals have lessened and there have been intervals where some concentrations have increased (Hung et al., 2016; AMAP, 2013). Given the opposing processes at play, it is not straightforward to detect the effect of CC on POPs concentrations in the Arctic and globally. Declines of chemicals in air are caused primarily by decreasing emissions due to worldwide regulations or restrictions, and continuing losses of the chemicals due to atmospheric reaction/degradation processes. The general decline in atmospheric concentrations is produced by an imbalance between supply of POPs to the atmosphere, now dominated by re-emission and emissions from waste streams/ stockpiles/ old equipment containing POPs, e.g. PCB transformers, and loss of POPs from the atmosphere as indicated by residence time. This imbalance can be affected by CC, which may enhance re-emission and emissions from landfills/stockpiles etc. (higher temperatures), but also increase rates of loss (degradation, scavenging by precipitation, etc.). To detect the effect of warming on POPs cycling in the Arctic, therefore, requires first accounting for, and mathematically removing, the other factors. Gao et al. (2010) and Ma et al. (2011) applied a detrending method to remove the linear trend in monitored POPs time series collected from the Great Lakes and two high arctic monitoring sites (Zeppelin and Alert) to reveal correlations between POPs and increasing air temperatures also an inverse correlation with declining arctic sea ice extent (Gao et al., 2010; Ma et al., 2011). These authors also developed a POPs perturbation model to elucidate the detrended data (Ma et al., 2010, 2011). The model (Section 2.2) assumed that the observed POPs concentrations are the sum of the mean and perturbed concentrations. Ma et al. (2011) found good agreement between 
detrended ambient concentrations and perturbed (modeled) concentrations of POPs at the arctic monitoring sites, implying that POPs have been remobilized into the Arctic atmosphere over the past two decades as a function of $\mathrm{CC}$ in the Arctic.

There has been ongoing debate on abrupt climate change and potential "tipping points" (Lenton, 2011; Duarte et al., 2012; Livina and Lenton, 2013; Holland et al., 2006). One obvious tipping point would be sea ice in the Arctic Ocean, which may be signaled by an abrupt decline in Arctic sea ice area to recorded low value in 2007, which has persisted over time (Livina and Lenton, 2013). Sea ice cover has been monitored for far longer than atmospheric POPs concentrations, and with greater accuracy since the 1970s when satellite data became available (e.g., Serreze and Stroeve, 2015). The large decline in September sea-ice cover, and especially after 2007, provides an obvious system change that could manifest itself in a large effect on air-sea exchange of POPs. Modeled perturbations of air concentration and water-air exchange flux of PCB-28 set against the rapid decline of sea ice cover in 2007 (Figure 4) shows that both the perturbed concentration anomaly $\mathrm{C}_{\mathrm{a}}{ }^{\prime}$ and the air-water exchange flux increased considerably in 2007, corresponding well with the large negative summer sea ice anomaly in the same year. Using various statistical techniques, Zhao et al. (2015) examined years exhibiting step changes in the time series of ambient POPs atmospheric concentrations measured at four arctic POPs monitoring sites. Most step changes, particularly for PCBs, were found in 2001-2002 and 2007-2008, with the latter corresponding to the step decrease in arctic sea ice concentration up to that time. Their finding suggests that, although over the long term the atmospheric POPs concentrations will decline due to decreasing primary emissions and general degradation in the environment, the sea-ice melt and strong 
warming in the Arctic, especially from 2007 onward, will render the effect of arctic climate change on POPs environmental fate more detectable due to more rapid air-sea exchange.

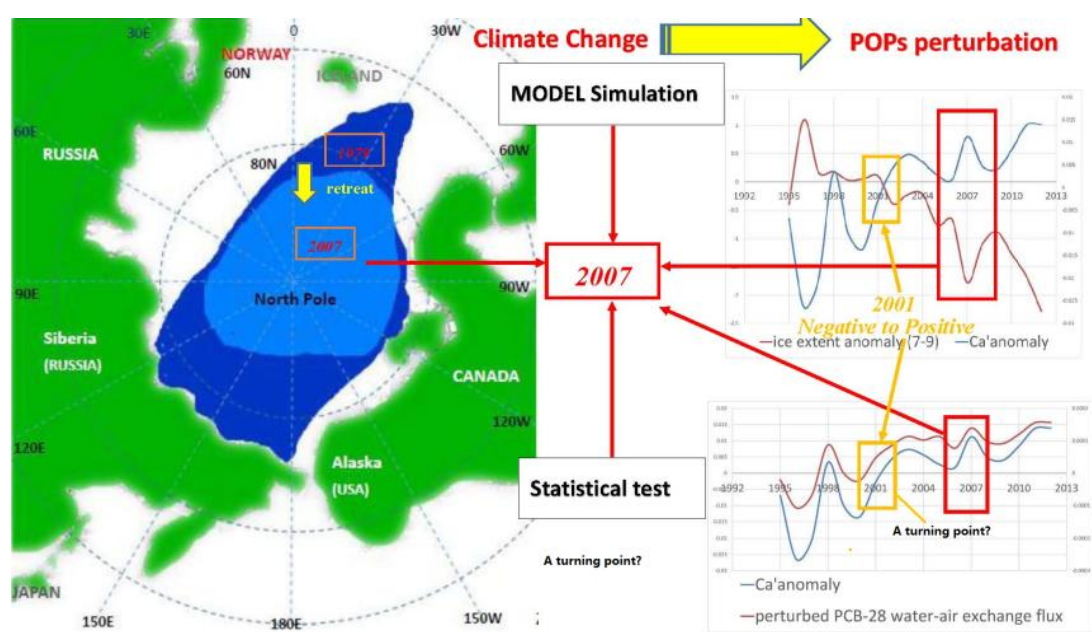

Figure 4. A schematic diagram the influence of rapid decline of arctic sea ice (left panel) in 2007 on modeled perturbations of air concentration and water-air exchange flux of PCB-28 (right panel). Upper right panel shows summer ice extent anomaly averaged over the Arctic and perturbed air concentration $\left(\mathrm{pg} \mathrm{m}^{-3}\right.$ ) of PCB-28, and lower right panel illustrates summer ice extent anomaly and perturbed air-water exchange flux of PCB-28.

Ice cores and sediment cores are often used to reconstruct contaminant records over many years and the history of deposition at the core site from which the contaminant use, emission, atmospheric transport, and other processes may be inferred. Ice and sediment core analysis therefore becomes an important option to investigate decadal or longer time scale effects of climate on POPs environmental cycling. Bogdal et al. (2009) analyzed POPs records in dated sediment cores collected from a hydroelectric proglacial reservoir lake fed by melt water from the Oberaar Glacier in the Alps. They found that, since the late 1990s, the input of many POPs into this high-alpine lake increased sharply such that by the mid 2000s, input fluxes of some of POPs were similar to or even higher than they were in the 1960s-1970s when the chemicals were heavily used. The authors proposed that the sharp increase in POPs level associated well with the accelerated melting of local 
alpine glaciers due to climate warming. Likewise, Wang et al. (2010) developed DDT and $\mathrm{HCH}$ profiles in ice cores collected from Mt. Everest (the Tibetan Plateau), Mt. Muztagata (the eastern Pamirs), and the Rocky Mountains from which they were able to draw connections between the Mt. Everest record and the ENSO index, between the Muztagata record and the Siberian High, and between the Rocky Mountain HCH record and the NAO.

\section{Model simulation and prediction of future POPs trends under projected climate change and emission scenarios}

Detection of an association between POPs environmental cycling and $\mathrm{CC}$ is subject to large uncertainties. These uncertainties are due primarily to (1) sparse air measurement data of POPs across the globe that are, as yet, too short to discriminate CC signatures at the decadal scale; (2) in the context of decadal or longer time-scale CC, changes in magnitude and direction of large-scale winds as a consequence of $\mathrm{CC}$ are more difficult to assess because such changes are not readily measurable (UNEP/AMAP, 2011); (3) there are very limited measurements of POPs in multi-media compartments (ocean, soil, ice/snow, permafrost), which makes it difficult to assess exchange of POPs between the atmosphere and these compartments, and the spatial distribution of POPs across the globe. To address these difficulties, modeling tools have been developed to examine the influence of long-term climate change on global distribution and levels of POPs under projected CC and emission scenarios in the $21^{\text {st }}$ century (MacLeod et al., 2005; Lamon et al., 2009; Ma and Cao, 2010; Wöhrnschimmel et al., 2013; Friedman et al., 2014; Octaviani et al., 2015).

To run POPs projections, these models usually prescribe $\mathrm{CC}$ and POPs emission scenarios. Perhaps the simplest type of model views the environment as a set of boxes 
among which POPs exchange according to their physical-chemical properties (i.e., the multimedia fugacity model, Mackay, 2001; Wania and Mackay, 1999). Fugacity is a mathematical expression of the thermodynamic potential of a given chemical to "escape" from a certain medium, which permits an evaluation of the spontaneous direction of processes like diffusion and partitioning. With some assumptions, fugacity can also be applied to the rate at which such processes proceed between various media. McKone et al. (1996) made perhaps the first attempt to apply a fugacity model to the question of risks posed by chemicals in a warming climate. For a chemical with high volatility, HCB, they found that a temperature increase of up to $5{ }^{\circ} \mathrm{C}$ from the current mean temperature would have little effect on risks to human health due to exposure to HCB in air and water. Using a global-scale multimedia fugacity model, MacLeod et al. (2005) found that the NAO would most likely have an effect on atmospheric PCB concentrations in winter and spring in Northern Europe and the Arctic. This model was subsequently extended to simulate changes in the global distribution of two PCB congeners, PCB-28 and PCB-153 under contrasting climate scenarios (Lamon et al., 2009). Using two scenarios, one representing the last twenty years of the 20th century [20CE scenario based on the third phase of the Coupled Model Intercomparison Project (CMIP3) "Climate of the 20th Century Experiment" $(20 \mathrm{C} 3 \mathrm{M})]$ and the other representing the global climate under the assumption of strong future greenhouse gas emissions [A2 scenario based on the $21^{\text {st }}$ century climate change scenario (SRES-A2)], they found that the higher temperatures projected by the A2 scenario led primarily to increased primary and secondary emissions through volatilization and, therefore, increased atmospheric concentrations. Lamon et al.'s (2009) modeling results also suggested that climate warming was one of the most 
significant factors determining the response of POPs cycling in the environment. Using the same model, Wöhrnschimmel et al. (2013) examined the difference in emissions and transport of POPs-like chemicals to the Arctic under the 20th century base-case climate change scenario (20C3M) and the SRES-A2 future climate scenario. For the period 2020-2050, they projected a $5 \% \mathrm{yr}^{-1}$ increase in primary emissions of PCB-153 north of $60^{\circ} \mathrm{N}$ due to increased industrial activity under ice-free conditions in the Arctic, and increased emissions of pesticides (e,g, $\alpha-\mathrm{HCH})$ as arable land expanded northward. Furthermore, this increase in primary emission resulted in as much as a factor of 2 increase in concentrations in air and water. After primary emission ceased, concentration levels could increase up to a factor of 2 in air and 4 in water, due mostly to changes in transport and fate of chemicals under the climate change scenario.

A more sophisticated modeling approach, e.g., the GEOS-Chem model, starts with a general circulation model and incorporates meteorology and its effect on chemical processes including partitioning and degradation. This model has been widely used for problems in global atmospheric transport of air pollutants (Bey et al., 2001). Using this model, Friedman et al. (2014) investigated the effects of projected 2000-2050 emissions and climate changes on the atmospheric transport of three polycyclic aromatic hydrocarbons (PAHs). By inputting projected declines in PAH emissions in 2050, they found a minor increase in modeled air concentrations of more volatile PAHs and a decrease in heavier PAHs, which tend to be particle bound in mid latitudes of the $\mathrm{NH}$, suggesting a "climate penalty" for volatile (mostly in gas-phase) PAHs and "climate benefit" for less volatile, particle-bound PAHs. Their modeling results also suggested that $\mathrm{CC}$ signals would be most observable in the Arctic, confirming strong response of 
observed ambient POPs concentrations to arctic warming (Section 3). Using the same model, Friedman and Selin (2016) compared the impact of local sources with long-distance transport and dynamics on atmospheric PCB concentrations in the Arctic. They found that processes outside the Arctic, such as volatilization and atmospheric LRT rather than secondary volatilization from the Arctic Ocean dominated long-term changes in PCBs within the Arctic. Hansen et al. (2015) also used an atmospheric transport model to simulate hemispheric distribution, poleward atmospheric transport and fate of POPs in the Arctic under the SRES A1B climate scenario. Their results revealed increased and decreased total mass of POPs in the NH and the Arctic depending on the physicochemical properties of targeted compounds in their model simulation. Using a coupled atmospheric general circulation model (GCM) and a chemical transport model, Octaviani et al. (2015) simulated the input into and output of DDT and PCBs from the Arctic under present day (1970-1999) and future (2070-2099) climates. Their model results indicated that the input of DDT to the Arctic would increase in the future whereas the output of PCB-153 from the Arctic would increase, both due to a more frequent occurrence of the positive phase of the $\mathrm{AO}$ and $\mathrm{NAO}$, which enhances meridional air mass transfer between the Arctic and southern latitudes.

When primary emissions and degradation half-lives dominate the dynamic balance of POPs in the atmosphere (Armitage et al., 2011), variance due to the more minor effects of climate change on other factors, such as atmospheric LRT, volatilization, and air-sea exchange is not readily detectable. Using the perturbation model (Section 2.2), Ma and Cao (2010) quantified changes in concentration of POPs in various media subject to fluctuating conditions of air temperature, snow and sea ice, winds, and precipitation (see 
section 2.2). For HCHs, PCBs and $\mathrm{HCB}$, the model predicted that an increase of 0.05 $0.1 \mathrm{~K} \mathrm{yr}^{-1}$ in the air temperature would lead to $4-50 \%$ increases in the perturbed air concentrations (Ma and Cao, 2010). The model was also applied to predict the perturbation in air concentrations of PCBs and HCHs likely to occur between 1991 to 2100 driven by air temperature and precipitation anomalies under the IPCC SRES-A1B emission scenario. For example, the relatively volatile PCB-52 increases in the arctic atmosphere and remains at higher values till about 2040 and decreases thereafter due to degradation (Figure 5). Perturbed concentrations of $\alpha-\mathrm{HCH}$ and several other lighter PCBs display similar temporal patterns. In contrast, more hydrophobic PCB-153 shows increasing trends throughout the $21^{\text {st }}$ century, potentially due to its tendency to remain in environmental sinks (e.g. sediment/soil and water) for longer periods of time.

Inference of the effects of CC on POPs in oceans has relied almost completely on models. Using a coupled hydrodynamic, fate and transport ocean model, O'Driscoll et al. (2014) simulated the response to CC of PCB-153, a hydrophobic POP, and $\gamma-\mathrm{HCH}$, a soluble POP, in the North Sea. Accounting for contributions from atmospheric deposition, riverine input and exchange with adjacent seas, and using the IPCC SRES-A1B scenario, the model showed that dry gas deposition and volatilization of $\gamma-\mathrm{HCH}$ will increase in the future, and volatilization in 2090-2099 will be even greater than 2046-2055. Overall, the model simulations indicated that CC as represented by the chosen IPCC scenario will have a negligible influence on the fate and transport of the two POPs in the North Sea. 


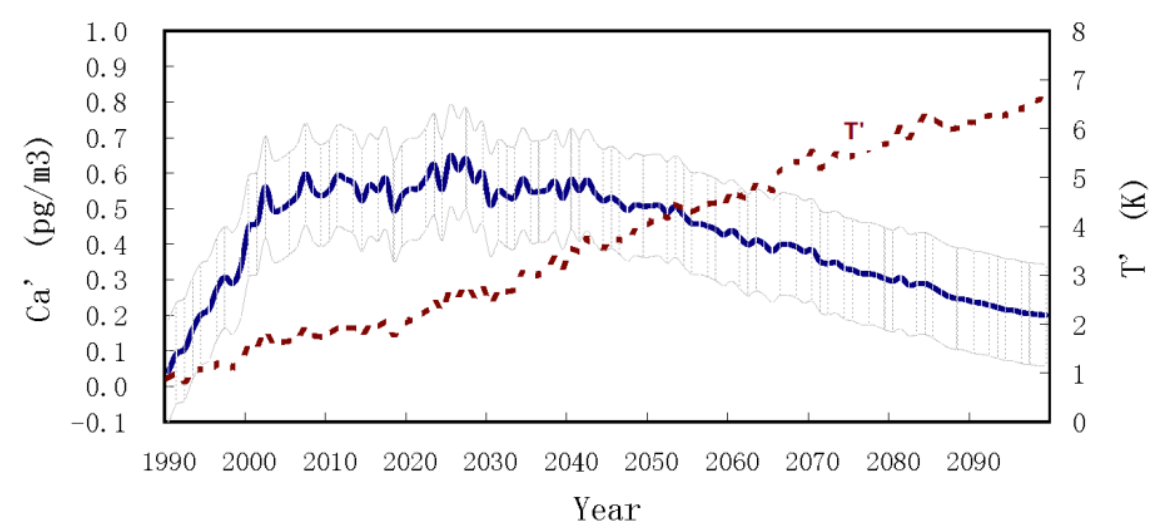

Figure 5. Perturbed atmospheric concentration $\left(C_{\mathrm{a}}{ }^{\prime}, \mathrm{pg} \mathrm{m}^{-3}\right)$ of PCB-52 averaged over the Arctic from 1990 to 2100, scaled on the left Y-axis (blue solid line), and mean temperature anomaly $(T, \mathrm{~K})$ averaged over the Arctic for the same period of time, scaled on the right Y-axis (deep red dashed line). Shading lines indicate standard deviations of perturbed air concentrations.

\section{Food web and wildlife exposure risk to POPs under a changing climate}

The major environmental concern with POPs has to do with toxicity. At high enough exposures, POPs have been shown variously to cause endocrine disruption, reproductive and immune dysfunction, neurobehavioral and developmental disorders, and cancer (World Health Organization, 2010). While adverse health effects associated with exposure to POPs have been observed in high trophic level wildlife and humans, evidence specifically connecting $\mathrm{CC}$ and adverse effects from POPs is lacking. The problem is partly one of complexity and partly one of inadequate data (Pacyna et al., 2015). As already shown, CC can affect transport of, and exposure to, chemicals. Models like those described above could clearly be applied to both aspects in the context of CC. However, toxicity from POPs undergoing LRT in the environment results from the chronic exposure of individuals or populations to mixtures of chemicals including POPs and other substances together with other stresses brought on by climate change. These other climate-related stresses (e.g., changes in temperature extremes, changes in food webs, transmission of diseases, invasive species, to mention but a few) increase the vulnerability of any given population to the further stress of POPs (Ross et al., 2013; 
Couillard et al., 2008).

There are many ways that $\mathrm{CC}$ can influence POPs bioaccumulation, including physical phenomena like sea ice loss or rising temperatures, and biological phenomena like altered food web structures, nutrition, and foraging behaviour. Given the strong bioaccumulation and biomagnification of many POPs in foodwebs and the persistence of POPs in the environment, our main concern is the potential for CC to release large quantities of legacy POPs presently stored in 'safe places' like sediments or glacial ice, thus permitting them to enter, or re-enter, foodwebs (section 2.4).

The potential for $\mathrm{CC}$ to affect POPs bioaccumulation in some way, or to alter pathways, and thereby have an effect on human health has been discussed in a number of articles (Macdonald et al., 2003; Jenssen, 2006; Noyes, 2009; Boxall et al., 2008; Borgå et al., 2010; Carrie et al., 2010; Ng and Gray, 2011; UNEP/AMAP, 2011; Gouin et al, 2013; UNEP/AMAP, 2011), but as yet there has been no quantitative linkage between POPs, CC and health.

What we worry about in contaminant assessments conducted by AMAP or the Canadian Northern Contaminants Program (NCP) is the risk of POPs present to the ecosystem and humans. Risk from a toxic chemical is a product of the hazard (toxicity) multiplied by the exposure (see for example, Gilbert, 2011, Macdonald and Bewers, 1996) The toxicities, or hazards, of chemicals are, in principle, measureable through laboratory studies, although toxicity of mixtures of toxic chemicals is far from well-studied (e.g., see Ross et al., 2013). Climate change, however, does not operate on hazard - it operates on the exposure component of the risk equation. If it were not for environmental concentrating processes, most POPs would present little risk because they would dilute as 
they mix into the environment, and eventually become removed through degradation and burial in sediments. In this context, $\mathrm{CC}$ as projected by the IPCC would appear generally to enhance diluting processes like mixing and degradation through warming and a generally more active hydrological cycle. However, the surprising exposures to POPs of high-trophic species living far from the points of emission underscores the importance of environmental concentrating processes. We contend, therefore, that $\mathrm{CC}$ is likely to have its strongest effect on risk by enhancing or diminishing these concentrating processes (e.g., see Macdonald et al., 2003; Houde et al., 2011). Although there are numerous environmental processes that concentrate POPs, these may be broadly classified into two fundamental categories (Macdonald et al., 2002). The first class of concentrating mechanisms is thermodynamically spontaneous, involves partitioning between media, and has only a small effect on POPs fugacity. These processes can be described and modeled using temperature-dependent equilibrium constants as described above for the multimedia fugacity models (Section 3), and therefore one can explore the consequence of CC on, for example, atmospheric transport and atmosphere-ocean partitioning by examining the effect of temperature rise or alteration in precipitation. The second class of mechanisms requires the input of energy; that is, the processes are not thermodynamically spontaneous and produce increases in POPs fugacities. In these processes some of the medium holding the contaminant (e.g., fat tissue) is removed (metabolized) but the contaminant remains behind at ever increasing concentration. Biomagnification in the food web is the most widely-recognized example of these processes, but there are many others associated with the carbon cycle and phase change of water (Macdonald et al., 2002). These processes are far more difficult to model in the context of CC because one 
cannot predict with certainty how $\mathrm{CC}$ will, for example, affect populations, predation, species distributions and other details in the carbon cycle.

The major exposure pathway of POPs for wildlife and humans is through diet with other entry points like drinking water, dermal contact, and inhalation of ambient air and particulates being generally of minor importance except for small animals like zooplankton where surface area to volume ratio is large (e.g., Pućko et al., 2013b). Aquatic food webs are particularly prone to biomagnification of hydrophobic, lipid-soluble POPs: on passing from air into water into the food web and on up to top aquatic predators, the cumulative concentration magnification for POPs can be as high as 7 to 9 orders of magnitude! Small changes in the multiplication factor at any point, therefore, can mean the difference between innocuous contamination and toxic exposure in the top predators. Based on these considerations, it is likely that the most important effects of $\mathrm{CC}$ on risk will be found in high trophic level aquatic species and in humans that depend on these for food.

Climate warming will increase vapour pressure and alter thermodynamic equilibria for partitioning of POPs among various environmental media. In general, one can expect that $\mathrm{CC}$ will cause POPs to be more actively transported in the vapour phase, but $\mathrm{CC}$ also will tend to favour the evasion of POPs out of the water and back into air. Warming also favours metabolism. Therefore, warming is likely to enhance risk through greater atmospheric transport, but reduce risk through partitioning and metabolism with the latter probably weighting the balance ultimately toward less risk.

But what about the non-thermodynamic concentrating processes? In the Arctic marine foodweb, biomagnification proceeds from, for example, phytoplankton to 
zooplankton to polar/arctic cod to ringed seal to polar bear (Figure 6), with the higher trophic levels contributing to the traditional diet of the indigenous peoples thus presenting risk (Vorkamp et al., 2004). Is there evidence that CC has had an effect on POPs exposure in the higher trophic levels? In a series of papers on polar bears, McKinney et al. $(2009 ; 2012 ; 2013 ; 2015)$ have examined how the widespread change in Arctic's sea-ice climate has impacted foraging and diet for this iconic species. Using stable isotope analyses and fatty acid fingerprinting along with POPs analyses for bear lipids, these authors have been able to show that bear diets have altered in response to changes in prey availability, and that this has altered contaminant exposure. It is, perhaps, not surprising that the best evidence assembled so far to make the case for CC-POPs interactions comes from the polar bear given that it is an apex marine predator exceptionally dependent on a sea-ice ecosystem, which has recently undergone drastic change. However, to make the case for such interactions also depends critically on having at hand appropriate time-series or baseline data that include not only POPs, but also evidence of bear diet and foraging (e.g., stable isotopes, fatty acid fingerprints). Exposures to POPs in a changing Arctic have been shown to weaken the polar bear's immune system due to high PCBs concentrations on their own (Bernhoft et al., 2000; Diez et al., 2013, 2015).

There are very few other examples that we are aware of to make firm connections between CC and POPs mostly because of the sparseness of time-series data. Recently Loseto et al. (2015) used a time series of mercury ( $\mathrm{Hg}$ ) burdens in western populations of beluga to seek connections between exposure to $\mathrm{Hg}$ and climate cycles represented by the AO, the Pacific Decadal Oscillation (PDO) and records of sea-ice minimum. The database, which was not ideal, consisted of 18 sampling events (females and males) 
between 1981 and 2011. Among the climate indices, the PDO was found to produce a significant relationship with an 8-year time lag. Beluga, which feed predominantly on cod and are an important source of traditional food for northerners, are clearly key species to monitor and thus a fairly long data base exists. This animal, which forages between the Bering and Beaufort Seas, is to some extent affected by ice cover for its migrations. Therefore, like the polar bear, one would expect CC to manifest itself in this animal's exposure to POPs. Likewise, Gaden et al. (2009) used a record of $\mathrm{Hg}$ muscle concentration in Beaufort Sea seals collected intermittently at 9 periods between 1973 and 2007 to propose a non-linear relationship between $\mathrm{Hg}$ exposure and sea-ice climate. No similar studies have been made for POPs in belugas; however one might expect POPs also to manifest effects of $\mathrm{CC}$ since they share important characteristics with $\mathrm{Hg}$ (widespread contamination historically from human activities, semi volatility, LRT facilitated by the atmosphere, and bioaccumulation /magnification in marine foodwebs). In this context, bowhead whales also have an inter-ocean foraging pathway (Bering and Beaufort Seas) and manifest the effects of seasonal changes in their foraging locations in the pattern of POPs carried in their fat (Hoekstra et al., 2002), but we are not aware of any studies that have examined bowhead whales in the context of POPs-CC interaction.

Perhaps the most serious impediment to detecting the effects of $\mathrm{CC}$ on top predators in the ocean is the general inadequacy of time series. Even though we can obtain long, unbroken temporal records of climate indices at sub-annual resolution, and long records for sea-ice cover, the sampling data base for marine predators is, at best, annual but often sporadic (e.g., 1 - 5 year gaps) and frequently do not include a comprehensive data set with POPs analyses, dietary composition and other ancillary data needed to interpret the 
results. A second issue is that, while there are reliable time series for air, and some time series for selected top predators (bears, beluga, seals, narwhal), there are virtually no time series for POPs in ocean water (possibly excepting HCHs). Given all of the sources of $\mathrm{CC}$-mediated variation possible between atmosphere and top aquatic predators, the lack of information on the central components of the POPs cycle makes it exceptionally hard to understand the processes involved even if correlations were found between apex feeders and, say, air trends.

Another way that $\mathrm{CC}$ can affect POPs through the carbon cycle is by altering phytoplankton dynamics and diversity (Henson et al., 2010). As mentioned in Section 2.4, change at the lowest trophic level can affect drawdown due to POPs uptake in phytoplankton, and subsequent sinking below the mixed layer. The phytoplankton, themselves, may exhibit growth dilution and other bioenergetic processes which are passed upward into zooplankton, predator fish and animals that feed on these. In one example evaluating exposure to $\mathrm{Hg}$, Foster et al., (2012) showed that even at the zooplankton trophic level, there can be substantive differences in trophic magnification factors depending on specific predator-prey linkages; there are no such data for POPs, but clearly CC can alter these linkages (UNEP/AMAP expert group, 2011), with consequences that may reduce exposure (Borgå et al., 2010) or increase exposure (Carrie et al., 2010) in predatory fish depending on the circumstances. In another example, contaminant concentrations in some top predator fish (salmon) in Lake Ontario were found to decrease with increasing summer temperatures (French et al., 2006). This link was attributed to the negative effect of warming temperatures on prey species, causing a decline in the abundance of the diet species that have a preference for cool to cold waters, 
thereby associated contamination level in fish with temperature. This finding was based on seasonal changes in temperature that were stronger than interannual and longer term temperature variability.

While scientists suspect that, generally, legacy POPs concentrations in food webs are declining in response to elimination from production and use (Rigét et al., 2010), the general warming trends and other changes in global ecosystems may at times and in some places oppose this general trend. For example, Bustnes et al. (2010) compared PCB, HCB, and oxychlordane data collected from glaucous gulls (Larus hyperboreus) blood/plasma from 1997 to 2006 at Bear Island (Bjørnøya) in the Barents Sea with the AO index. Using a regression model, these authors found a negative correlation between POPs and the winter AO index and a positive relationship between POPs and the previous summer's or winter's AO indices. They proposed that the strongest relationship, which was between POPs and previous winter's AO index, was produced by the poleward transport of industrial chemicals from North America and Europe favoured by positive AO conditions. Of the three chemicals, HCB had the strongest correlation with the AO index, likely due to its longer residence time in the atmosphere [with an atmospheric half-life of 306 day (Beyer et al., 2000)] and greater volatility. The consequence that gulls have relatively higher POPs concentrations in breeding seasons following years with high air transport toward the Arctic provides direct evidence that climate variability at the decadal scale can produce increasing exposure even where trends are generally downwards.

Using statistical approaches similar to those used by Bustnes et al. (2010), Rigét et al. (2013) found correlations between POPs in blubber of ringed seals and several climate indices including the AO Index, winter sea-ice coverage (November-May), the number 
of sea-ice days during winter, summer mean water temperature and salinity in central western Greenland. Statistically significant correlations were found between PCB-52 and -153 and the number of winter sea ice days, $\alpha-\mathrm{HCH}$ and the preceding winter's AO Index, and $\beta-\mathrm{HCH}$ and the preceding summer's salinity. Among these relationships, $\mathrm{PCB}$ and p,p'-DDE were positively correlated with the AO Index and $\alpha-\mathrm{HCH}$ was negatively correlated with the AO Index. These results lead to conclusions similar to those of the Bustnes et al.'s study: conditions favouring poleward atmospheric transport deliver warm air masses that reduce sea ice cover and alter sea ice distribution. $\alpha-\mathrm{HCH}$ is more volatile, thus readily transported in air, but partitions more strongly into cold water $(H=0.082$ $\mathrm{Pa} \cdot \mathrm{m}^{3} / \mathrm{mol}$ at $0{ }^{\circ} \mathrm{C}$, Xiao et al. , 2004) than PCB-153 $\left(H=17 \mathrm{~Pa} \cdot \mathrm{m}^{3} / \mathrm{mol}\right.$ at $0{ }^{\circ} \mathrm{C}$, Schenker et al., 2005) or p,p'-DDE ( $H=0.39 \mathrm{~Pa} \cdot \mathrm{m}^{3} / \mathrm{mol}$, Shen and Wania, 2005). Decreasing sea ice area enhances air-sea exchange and thus permits $\alpha-\mathrm{HCH}$ to escape from water to air, reducing its concentration in water and, subsequently, its concentration in the marine food web supporting seals. Rigét et al. (2013) proposed that years with strong ice cover (high number of sea-ice days) led to lower concentrations of PCB-153 in ringed seals due to the reduction in availability of fish and amphipods for seals to forage upon. Ocean currents have also been shown to carry climate signals. For example, positive correlations found between salinity at Fyllas Banke, west Greenland Sea and $\beta-\mathrm{HCH}, \mathrm{PCB}-52$, and p,p'-DDE was interpreted by Rigét et al. (2013) as evidence that these chemicals were associated with the relatively saline Irminger Current, derived from North America, rather than the East Greenland Current derived from North America. Variability in the strength of source-water currents, therefore, led to variability in the POPs concentrations. Likewise, Li et al. (2002) concluded that $\beta-\mathrm{HCH}$ was strongly deposited from the 
atmosphere into the surface waters of the Bering Sea, thence to transport into the Arctic Ocean via currents entering through Bering Strait. The strength of deposition of $\beta$ - $\mathrm{HCH}$ into the Bering Sea depends on rainfall and the subsequent transport to the Arctic Ocean depends on the inflowing current, which is supplied partly by the Anadyr current and partly by the Alaska coastal current; these factors all vary at the decadal scale with climate (Weingartner et al., 1999; Luchin and Paneled, 2014; Woodgate et al., 2006). Therefore, for the western Arctic Ocean, $\beta-\mathrm{HCH}$ variability (and probably other POPs to some degree) is directly related to ocean current variability. Once entering the Arctic Ocean, $\beta-\mathrm{HCH}$ may then produce higher concentrations in arctic air due to outgassing forced by reduced emissions and warming water, facilitated by loss of summer ice cover. - Marine systems have provided some of the best examples of where CC and POPs interactions are occurring, POPs exposure in terrigenous ecosystems are also likely affected by CC. For example, arctic foxes feed out of both marine (ringed-seal and seabird carcasses) and terrigenous (ptarmigan, reindeer, geese) systems; Anderson et al. (2015) showed that fox diets have varied over the past two decades due to change in food availability caused by climate-related factors like increasing mortality of Svalbard reindeer and loss of access to marine food sources due to sea ice melting. These sorts of changes alter not only the magnitude of exposure [i.e., POPs are at higher concentrations in marine food than terrestrial food (Fuglei et al., 2007)], but also the composition of the POPs [see for example, Christensen et al. (2005)]. The net result of these CC effects on the two food webs led directly to reduced exposure to POPs for arctic foxes. This particular example has direct relevance to native populations in the Arctic because they depend on both terrigenous and marine ecosystems for much of their sustenance, and 
opportunities to forage on these animals depends strongly on a number of factors affected by CC including population density, migratory patterns, ice cover, and permafrost.

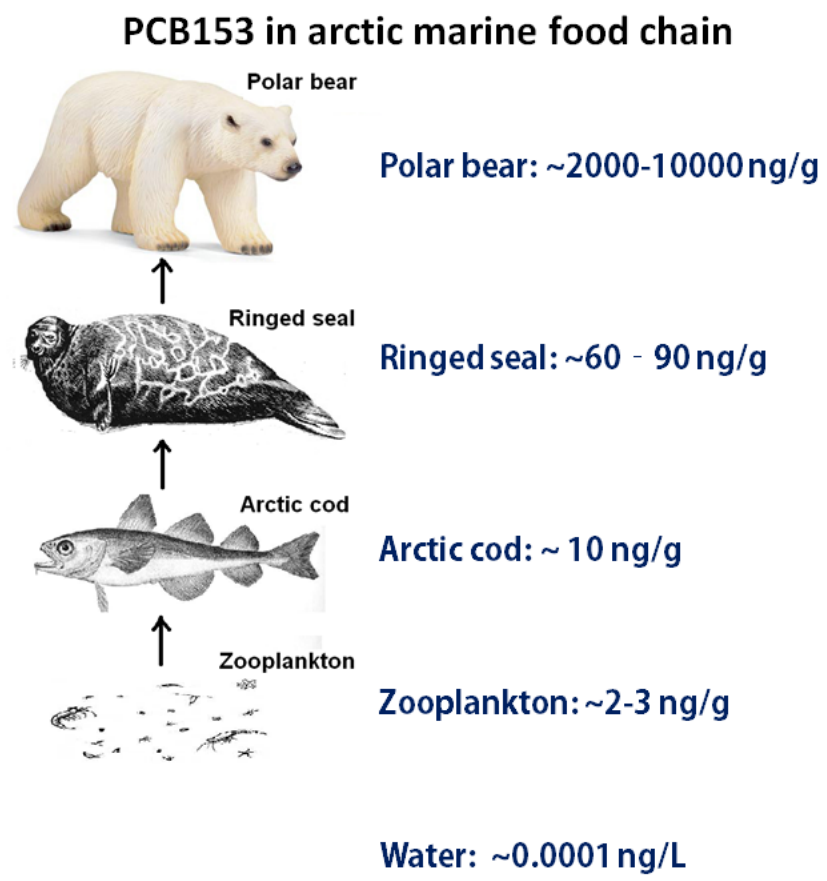

Figure 6. Schematic view of PCB-153 bioaccumulation and bioamplification in typical arctic marine food web. The sources of lipid concentrations are collected from Carrizo and Gustafsson (2011, water), Kelly (2006, arctic cod, ringed seal), Muir et al. (2000, ringed seal), Vorkamp et al. (2011, ringed seal), and Letcher et al. (2010, polar bear).

A variety of models have addressed interactions between climate change, carbon cycle, foodwebs and POPs. For example, physical-biological coupled models have been used to project how CC might affect lower trophic levels [Nutrients, Phytoplankton, Zooplankton (NPZ)] (e.g., Lavoie et al., 2010), multi-media environmental models have been used to examine how $\mathrm{CC}$ might affect the interaction between POPs and the carbon cycle [e.g., the GloboPOP model applied by Armitage and Wania(2013)], or how changing ocean temperature might affect primary production and thereby affect POPs bioaccumulation (Borgå et al, 2010) and, of course, multi-media models have been 
frequently applied to the problem of POPs distributions in foodwebs (e.g., Mackay, 2001; Gouin et al., 2013). However, to our knowledge, no models incorporating physically-based GCMs to deal with climate change in the physical and lower trophic level systems, have been coupled with multimedia POPs models of the higher trophic levels in order to explore questions of climate -POPs interactions (and see UNEP/AMAP expert group, 2011). Hence, to make progress in prediction and understanding how CC alters pathways, such coupled models need to be developed. Borgå et al. (2010) constructed a model based on the hypothesis that increase in water and air temperatures would alter partitioning of organic compounds thereby affecting uptake. Their model was based on projected increases in temperature in the Arctic of $2.0^{\circ} \mathrm{C}$ and $4.0^{\circ} \mathrm{C}$, and taking into consideration such factors as the rates of feeding, ventilation, biotransformation and growth for invertebrates and fish. In the model, a doubling of primary production over the Arctic shelves, due to the reduced sea ice cover and enhanced upwelling, led to an increase in particulate organic carbon (POC). The increase in temperature and POC together then led to reduced bioaccumulation of PCBs. Coupled bioenergetic and bioaccumulation models applied to the Great Lakes (Ng and Gray, 2011) found that bioaccumulation of PCB-77 for species in a typical predator-prey relationship (lake troutround goby) may have unexpected responses to contaminant cycling, due to the dynamics of uptake rates, growth dilution, and interaction between species with different temperature sensitivities. In the model, metabolic effects (temperature effects on the rate of chemical uptake and loss) were confounded by trophic interactions among species with different thermal sensitivities, which would promote invasions of warm-water species. Changes in PCB-77 concentrations in fish due to projected warming in Lakes Erie and 
Superior were relatively small, particularly when compared with potential changes in food availability and food type. These and other models (e.g., see Gouin et al., 2013) emphasize that CC insofar as carbon and POPs cycles are concerned, is far more than a simple effect of temperature on thermodynamic partitioning and kinetic rates. Rather, one needs to address also a number of biological factors like growth rates, feeding preferences, foraging, and species redistributions based on thermal niches (i.e., invasions, migrations, extinctions) due to the altered climate. Gouin et al. (2013) concluded that the effects of projected global climate change on long-term chemical transport, partitioning, and fate are relatively small for persistent neutral organics, but CC-induced effects on bioaccumulation potential in aquatic foodwebs may vary substantially depending on partitioning properties and biotransformation rate constants. They also point out the many uncertainties in simulating the effect of CC scenarios on POPs cycling in biotic and abiotic environments, including primary and secondary emissions, physicochemical properties, environmental cycling, bioaccumulation, and, of course, in the projected CC scenarios themselves.

\section{Conclusions}

Persistent organic pollutants have been released to the environment predominantly since the Second World War. Although the timing of use varies between individual POPs (e.g., PCBs and DDT were used much earlier than PBDEs), they all tend to exhibit a similar pattern of use: after introduction, there is a period of rapidly increasing emissions followed by restrictions or regulations, which sharply curtail these primary emissions. Since POPs are semi-volatile, they enter the atmosphere where they may be distributed rapidly and widely. However, the tendency for POPs to partition to particulates, soil, 
water and vegetation leads to a cumulative loading of these reservoirs during the period of high use. Once the primary emissions have been put under regulation, these environmental reservoirs (secondary sources), together with stockpiles and waste streams, then become far more important in the continued cycling of POPs. Temperature and organic carbon content, which are important control factors on the secondary sources, provide the mechanisms whereby climate change may alter the stability of POPs and the relative abilities of the environmental reservoirs to retain POPs, thus affect re-cycling between reservoirs.

Global warming tends to favour re-volatilization to air and farther transport of legacy POPs, including those stored in wastes and other industrial reservoirs from past use (e.g., old transformers, stockpiles, dumps). Enhanced exchange to air has been demonstrated by increasing air concentrations of POPs associated with warm phases of El Nino and NAO. In addition, the loss of frozen phases in the cryosphere (e.g., glaciers, permanent snow, permafrost, sea ice) releases legacy POPs and alters the rate of exchange of POPs between ocean and atmosphere. The advection of POPs by winds in the NH is affected by ENSO and NAO, both of which contribute to interannual variability. However, a clear linkage between POPs cycling in the atmosphere and decadal or longer time-scale climate change has not yet been demonstrated, likely due to the natural variability of the magnitude and direction of global winds. However, we can say with certainty that projected warming will generally increase the potential for POPs to undergo LRT, especially for the more volatile chemicals. Change in precipitation (amount, snow/water) associated with $\mathrm{CC}$ has not been shown to affect the environmental fate of POPs compared with the effect of rising temperature. 
The association between POPs fate in the ocean and $\mathrm{CC}$ has been identified predominantly from time series of air-water exchange. Climate warming generally favours the volatilization of POPs from surface ocean, lakes and rivers to air. Due to the atmospheric reductions in POPs concentrations produced by reduced primary emissions and degradation, we have witnessed the reversal of air-sea exchange for some POPs in certain part of oceans, such as the south Pacific Ocean and the Arctic Ocean, suggesting that these oceans have become sources to the atmosphere for these POPs. This has been especially true for POPs that have low Henry's law constants (e.g., the HCHs). Warming of the surface ocean would tend to enhance the reversal and thereby buffer, or delay, the decline of atmospheric POPs due to emission controls. The effect of $\mathrm{CC}$ on air-sea exchange occurs most significantly in the Arctic Ocean partly due to the large increases in surface temperature observed in some locations and partly due to the widespread loss of seasonal ice cover, which permits more rapid exchange of POPs. Furthermore, the organic carbon cycle in the ocean likely provides an important process where $\mathrm{CC}$ may alter the dynamic balance of POPs between air and water. The biological pump, which comprises the vertical flux of organic-rich matter from the surface ocean to deep ocean, also removes POPs from the sea surface. Increase or decrease in the biological pump due to $\mathrm{CC}$ would produce an increase or decrease in air-to-water net exchange, thus affecting the relative proportion of POPs that remain in the atmosphere or enter the deep ocean. Changes in the relative proportion of POPs in air and water induced by CC may pose unknown risks which vary with locations. Little is known about the levels of tolerance of different species for different mixture combinations.

Direct linkage between POPs in wildlife and climate variability has been observed 
mostly as the association between seasonal and interannual variation of atmospheric circulation and changes in POPs concentration in wildlife, or changes in exposure associated with changes in seasonal sea-ice cover. Climate induced changes in food-web structure and function provide indirect connections between CC and POPs contamination to wildlife. For example, warming and loss of ice cover permits the northward migration of marine species usually found farther south, which may produce altered exposure to POPs via food-web pathways, even if the migratory transport of POPs is small relative to quantities transported by winds or currents. Altered ice climate also presents the likelihood of altered foraging patterns and feeding opportunities for apex feeders like seals, whales, birds and bears.

Presently, many of the changes in POPs cycling associated with $\mathrm{CC}$ remain speculative because of knowledge gaps and uncertainties in understanding the associations between CC and POPs in biotic and abiotic environment, some of which have been listed previously [e.g., UNEP/AMAP (2011)]. Perhaps the greatest hurdle to defining the role CC may play in POPs cycles is the lack of coordinated, multi-media, long-term monitoring programs for POPs, which would provide a robust basis to validate models. This challenge is compounded by the fact that monitoring data lack geographical coverage and monitoring duration that are of the same spatial and temporal scales that climate change acts. Most long-term ( $>20$ years) monitoring data of POPs are from the Arctic, North America and western Europe while comparable datasets are lacking in large parts of the southern hemisphere, eastern Europe, Russia, and Asia. Furthermore, huge uncertainties exist in emission inventories which are essential input parameters that drive models. PCBs and $\mathrm{HCHs}$ are probably the only POPs for which better emission 
inventories have been developed. Encouragingly, most legacy POPs in the environment and wildlife have been declining subsequent to worldwide controls on their use. This general decline plus declines due to environmental degradation makes it difficult to discriminate the specific role that CC may have in producing the observed trends of POPs with time. Model predictions suggest that CC plays a moderating, or secondary, role in the long-term trends of POPs. It should be noted, however, that knowledge gaps and complex interactions between multiple environmental compartments make it extremely difficult to isolate the effect of CC on POPs trends as revealed by scarce time series data. Therefore, large effort is still needed to collect field data and improve model tools, and to enhance our understanding of POPs behaviors and fate in biotic and abiotic environments in a changing climate.

To date, the best time series data have been collected for air, and it is these data sets against climate variables (e.g., ENSO, NAO) that have provided the best evidence for CC-POPs linkage. To be able to draw clear connections between the atmospheric record and high trophic species at risk from POPs, we need far better time-series data for intermediate components of POPs pathways including water, zooplankton and high trophic levels. Time series for vertical flux (biological pump) and its POP content would also be an exceptionally useful parameter to monitor the intermediary role played by the upper ocean in POPs pathways.

The predominant effects of $\mathrm{CC}$ on POPs in the atmosphere can be captured by GCMs using partitioning coefficients and kinetic rates of degradation and transformation. These can be modeled by incorporating temperature into thermodynamic and kinetic processes, which has led to some success in projecting the effects of CC. This sharply 
contrasts aquatic systems in that the physical parameters, while important, are accompanied by changes in the carbon cycle which offer non-thermodynamic processes (solvent reduction) like the food-web and microbial degradation, with the result that modeling must also incorporate biology.

Future progress would require the application of physical GCMs to the atmosphere-ocean system as a physical basis for exploring IPCC scenarios, coupled to realistic NPZ (nutrient, phytoplankton, zooplankton) models for the ocean to reflect the lower end of the trophic system. Additional model components would then be required to capture the behaviour of higher trophic levels, which migrate, forage widely and are, themselves, undergoing stress from CC.

\section{Acknowledgements}

Jianmin Ma wishes to thank the National Science Foundation of China for financial support under grants 41371478 and 41371453 . Hayley Hung would like to acknowledge the Northern Contaminants Program (NCP) (Indigenous and Northern Affairs Canada) for financial support. Robie Macdonald gratefully acknowledges the Department of Fisheries and Oceans for support under its Emeritus program.

\section{References}

Åkerblom, S., Meili, M.,Bishop, K., 2015. Organic matter in rain: an overlooked influence on mercury deposition. Environmental Science \& Technology Letters, 2, 128-132.

AMAP, 2013. AMAP Assessment 2013: Arctic Ocean Acidification. Arctic Monitoring and Assessment Programme (AMAP), Oslo, Norway, pp. 99pp

AMAP, 2014. Trends in Stockholm Convention Persistent Organic Pollutants (POPs) in Arctic Air, Human media and Biota. By: S. Wilson, H. Hung, A. Katsoyiannis, D. Kong, J. van Oostdam, F. Riget, A. Bignert. AMAP Technical Report to the Stockholm Convention. AMAP 
Technical Report No. 7 (2014), Arctic Monitoring and Assessment Programme (AMAP), Oslo, Norway, pp. 54

Andersen, M. S., Fuglei, E., König, M., Lipasti, I., Åshild Ø. Pedersen, Polder, A., Yoccoz, N.G., Routti, H., 2015. Levels and temporal trends of persistent organic pollutants (POPs) in arctic foxes (Vulpes lagopus) from Svalbard in relation to dietary habits and food availability. Science of the Total Environment, 511, 112-122.

Arellano, L., Fernandez, P., Tatosova, J., Stuchlik, E., Grimalt, J.O., 2011. Long-range transported atmospheric pollutants in snowpacks accumulated at different altitudes in the Tatra Mountains (Slovakia). Environmental Science \& Technology, 45, 9268-9275.

Armitage, J.M., Quinn, C.L., Wania, F., 2011. Global climate change and contaminants - an overview of opportunities and priorities for modelling the potential implications for long-term human exposure to organic compounds in the Arctic. Journal of Environment Monitoring, 13(6), $1432-1546$.

Armitage, J.M., Wania, F., 2013. Exploring the potential influence of climate change and particulate organic carbon scenarios on the fate of neutral organic contaminants in the Arctic environment. Environmental Science: Processes \& Impacts, 15, 2263-2272.

Arrigo, K.R., van Dijken, G., 2015. Continued increases in Arctic Ocean primary production. Progress in Oceanography, 136, 60-70.

Bailey, R., Barrie, L.A., Halsall C.J., Fellin, P., Muir, D.C.G., 2000. Atmospheric organochlorine pesticides in the western Canadian Arctic: Evidence of transpacific transport. Journal of Geophysical Research, 105(D9), 11805-11811.

Becker, S., Hallsall, C.J., Tych, W., Kallenborn, R., Su, Y., Hung, H., 2008. Long-term trends in atmospheric concentrations of $\alpha$ - and $\gamma-\mathrm{HCH}$ in the Arctic provide insight into the effects of legislation and climatic fluctuations on contaminants levels. Atmospheric Environment, 42, 8225-8233.

Becker, S., Halsall, C.J., Tych, W., Kallenborn, R., Schlabach, M., Manø, S., 2012. Changing sources and environmental factors reduce the rates of decline of organochlorine pesticides in the Arctic Atmosphere. Atmospheric Chemistry and Physics, 12, 4033-4044.

Bellamy, P.H., Loveland, P.J., Bradley, R.I., Lark, R.M., Kirk, G.J.D., 2005. Carbon losses from all soils across England and Wales 1978-2003. Nature, 437(7056), 245-248.

Bennett, D., Kastenberg, W., McKone, T.E., 1999. General formulation of characteristic time for persistent chemicals in a multimedia environment. Environmental Science \& Technology, 33, 503-509.

Bennett, D., Scheringer, M., McKone, T.E., Hungrbühler, K., 2001. Predicting long-range transport: A systematic evaluation of two multimedia transport models. Environmental Science \& Technology, 35, 1181-1189.

Berg, M.V., Birnbaum, L.S., Denison, M., Vito, M.D., Farland, W., Feeley, M., 2006. The 2005 World Health Organization reevaluation of human and mammalian toxic equivalency factors for dioxins and dioxin-like compounds. Toxicological Sciences, 93, 223-241.

Bernhoft, A., Skaare, J.U., Wiig, Ø., Derocher, A.E., Larsen, H.J., 2000. Possible immunotoxic effects of organochlorines in polar bears (Ursus maritmus) at Svalbard. Journal of Toxicology and Environmental Health Part A, 59(7), 101-114.

Bey, I., Jacob, D.J., Yantosca, R.M., Logan, J.A., Field, B.D., Fiore, A.M., Li, Q.B., Liu, H.Y., Mickley, L.J., Schultz, M.G., 2001. Global modeling of tropospheric chemistry with assimilated meteorology: Model description and evaluation. Journal of Geophysical Research-Atmosphere, 106, 23073-23095. 
Beyer, A., Mackay, D., Matthies, M., Wania, F., Webster, E., 2000. Assessing long-range transport potential of persistent organic pollutants. Environmental Science \& Technology, 34, 699-703.

Beyer, A., Wania, F., Gouin, T., Mackay, D., Matthies, M., 2003. Temperature dependent of the characteristic travel distance. Environmental Science \& Technology, 37, 766-771.

Bidleman, T.F., Kylin, H., Jantunen, L.M., Helm, P.A., Macdonald, R.W., 2007. Hexachlorocyclohexanes ( $\mathrm{HCHs})$ in the Canadian Archipelago. 1. Spatial distribution and pathways of alpha-, beta- and gamma-HCHs in surface water. Environmental Science \& Technology, 41(8), 2688-2695.

Bidleman, T.F., Jantunen, L.M., Kurt-Karakus, P.B., Wong, F., 2012. Chiral persistent organic pollutants as tracers of atmospheric sources and fate: review and prospects for investigating climate change influences. Atmospheric Pollution Research, 3(4), 371-382.

Bidleman, T.F., Stern, G.A., Tomy, G.T., Hargrave, B.T., Jantunen, L.M. Macdonald, R.W., 2013. Scavenging amphipods - sentinels for penetration of mercury and persistent organic chemicals into food webs of the deep Arctic Ocean. Environmental Science \&Technology, 47, 5553-5561.

Bishop, J.K.B., 1989. Regional extremes in particulate matter composition and flux: effects on the chemistry of the ocean interior. In: Berger, W.H., Smetacek, V.S., Wefer, G. (Eds.), Productivity of the Ocean: Present and Past. J. Wiley \& Sons Limited, Dahlem, pp. 117-137

Blais, J.M., Schindler, D.W., Muir, D.C.G., Sharp, M., Donald, D., Lafreniere, M., Braekevelt, E., Strachan, W.M.J., 2001. Melting glaciers: A major source of persistent organochlorines to subalpine Bow Lake in Banff National Park, Canada. AMBIO: A Journal of the Human Environment, 30(7), 410-415.

Boetius, A., Albrecht, S., Bakker, K., Bienhold, C., Felden, J., Fernández-Méndez, M., Hendricks, S., Katlein, C., Lalande, C., Krumpen, T., Nicolaus, M., Peeken, I., Rabe, B., Rogacheva, A., Rybakova, E., Somavilla, R., Wenzhöfer, F., 2013. Export of algal biomass from the melting Arctic sea ice. Science, 339, 1430-1432.

Bogdal, C., Schmid, P., Zennegg, M., Anselmetti, F.S., Scheringer, M., Hungerbuhler, L.K., 2009. Blast from the past: melting glaciers as a relevant source for persistent organic pollutants, Environment Science \& Technology, 43, 8173-8177.

Bogdal, C., Divna, N., Luthi, M.P., Schenker, U., Scheringer, M., Hungerbuhler, K., 2010. Release of legacy pollutants from melting glaciers: Model evidence and conceptual understanding. Environmental Science \& Technology, 44, 4063-4069.

Bond-Lamberty, B., Thomson, A., 2010. Temperature-associated increases in the global soil respiration record. Nature, 464, 579-582. DOI: 10.1038/nature08930.

Borgå, K., Saloranta, T.M., Ruus, A., 2010. Simulating climate change induced alterations in bioaccumulation of organic contaminants in an Arctic marine food web. Environmental Toxicology and Chemistry, 29, 1349-1357.

Boxall, A.B.A., Hardy, A., Beulke, S., Boucard, T., Burgin, L., Falloon, P.D., Haygarth, P.M., Hutchinson, T., Kovats, R.S., Leonardi, G., Levy, L.S., Nichols, G., Parsons, S.A., Potts, L., Stone, D., Topp, E., Turley, D.B., Walsh, K., Wellington, E.M.H., Williams, R.J., 2008. Impacts of climate change on indirect human exposure to pathogens and chemicals from agriculture. Environmental Health Perspective, 117, 508-514.

Breivik, K., Sweetman, A., Pacyna, J.M., Jones, K.C., 2007. Towards a global historical emission inventory for selected PCB congeners-A mass balance approach-3. An update. Science of the Total Environment, 377, 296-307. 
Bustnes, J.O., Gabrielsen, G.W. Verreault, J., 2010. Climate variability and temporal trends of persistent organic pollutants in the arctic: a study of glaucous gulls. Environmental Science \& Technology, 44, 3155-3161.

Cabanes, A., Legagneux, L., Domine, F., 2003. Rate of evolution of the specific surface area of surface snow layers. Environmental Science \& Technology, 37, 661-666.

Cabrerizo, A., Dachs, J., Barcel, D., 2009. Development of a soil fugacity sampler for determination of air-soil partitioning of persistent organic pollutants under field controlled conditions. Environmental Science \& Technology, 43, 8257-8263

Cabrerizo, A., Dachs, J., Moeckel, C., Ojeda, M.J., Caballero, G., Barcelo, D., Jones, K.C., 2011. Factors influencing the soil-air partitioning and the strength of soils as a secondary source of polychlorinated biphenyls to the atmosphere. Environmental Science \& Technology, 45, 4785-4792.

Cabrerizo, A., Dachs, J., Barcelo, D., Jones, K.C., 2012. Influence of organic matter content and human activities on the occurrence of organic pollutants in antarctic soils, lichens, grass, and mosses. Environmental Science \& Technology, 46, 1396-1405.

Callaghan, T.V., Johansson, M., Brown, R.D., Groisman, P.Y., Labba, N., Radionov, V., Bradley, R.S., Blangy, S., Bulygina, O.N., Christensen, T.R., Colman, J.E., Essery, R.L.H., Forbes, B.C., Forchhammer, M.C., Golubev, V.N., Honrath, R.E., Juday, G.P., Mescherskava, A.V., Pheonix, G.K., Pomeroy, J., Rautio, A., Robinson, D.A., Schmidy, N.M., Serreze, M.C., Shevchenko, V.P., Shiklomanov, A.I., Shmakin, A.B., Sköld, P., Sturm, M., Woo, M.-K., Wood, E.F., 2011. Multiple effects of changes in Arctic snow cover. AMBIO: A Journal of the Human Environment, 40, 32-45.

Cao, M.K., Woodward, F.I., 1998a. Dynamic responses of terrestrial ecosystem carbon cycling to global climate change. Nature, 393, 249-252.

Cao, M.K., Woodward, F.I., 1998b. Net primary and ecosystem productions and carbon stocks of terrestrial ecosystems and their response to climate change. Global Change Biology, 4, $185-198$.

Carmack, E., Polyakov, I., Padman, L., Fer, E., Hunke, E., Hutchings, J., Jackson, J., Kelley, D., Kwok, R., Layton, C., Melling, H., Perovich, D., Persson, O., Ruddick, B., Timmermans, M.-L., Tolle, J., Ross, T., Vavrus, S., Winsor, P., 2015. Towards quantifying the increasing role of ocean heat in sea ice loss in the new Arctic. Bulletin of the American Meteorological Society, 96 (12), 2079-2105. DOI:10.1175/BAMS-D-13-00177.1.

Carrie, J., Wang, F., Sanei, H., Macdonald, R.W., Outridge, P.M., Stern, G.A., 2010. Increasing contaminant burdens in an Arctic fish, Burbot (Lota lota), in a warming climate. Environmental Science \& Technology, 44, 316-322.

Carrizo, D., Gustafsson, O., 2011. Distribution and inventories of polychlorinated biphenyls in the polar mixed layer of seven pan-Arctic shelf seas and the interior basins. Environmental Science \& Technology, 45, 1420-1427.

Cetin, B., Ozerb, S., Sofuoglub, A., Odabasi, M., 2006. Determination of Henry's law constants of organochlorine pesticides in deionized and saline water as a function of temperature. Atmospheric Environment, 40, 4538-4546.

Chen, C.R., Xu, Z.H., 2010. Forest ecosystem responses to environmental changes: the key regulatory role of biogeochemical cycling. Journal of Soils and Sediments, 10, 210-214.

Christensen, J.R., MacDuffee, M., Macdonald, R.W., Whiticar, M., Ross, P.S., 2005. Pacific salmon deliver persistent organic pollutants to British Columbia grizzly bears. Environmental Science \& Technology, 39, 6952-6960. 
Comiso, J.C., Hall, D.K., 2014. Climate trends in the Arctic as observed from space. WIREs Climate Change, 5, 389-409.

Corsolini, S., Borghesi, N., Schiamone, A., Focardi, S., 2007. Polybrominated diphenyl ethers, polychlorinated dibenzo-dioxins, -furans, and -biphenyls in three species of Antarctic penguins. Environmental Science and Pollution Research, 14, 421-429.

Cortes, D.R., Basu, I., Sweet, C.W., Brice, K.A., Hoff, R.M., Hites, R.A., 1998. Temporal trends in gas-phase concentrations of chlorinated pesticides measured at the shores of the Great Lakes. Environmental Science \& Technology, 32, 1920-1927.

Couillard, C.M., Courtenay, S.C., Macdonald, R.W., 2008. Chemical-environment interactions affecting the risk of impacts on aquatic organisms: A review with a Canadian perspective interactions affecting vulnerability. Environmental Reviews, 16, 19-44.

Cousins, I.T., Gevao, B., Jones, K.C., 1999. Measuring and modelling the vertical distribution of semivolatile organic compounds in soils. I: PCB and PAH soil core data. Chemosphere, 39 (14), 2507-2518.

Dachs, J., Eisenreich, S.J., Baker, J.E., Ko, F.C., Jeremiason, J.D., 1999. Coupling of phytoplankton uptake and air-water exchange of persistent organic pollutants. Environmental Science \& Technology, 33(20), 3653-3660.

Dachs, J., Lohmann, R., Ockenden, W.A., Mejanelle, L., Eisenreich, S.J., Jones, K.C., 2002. Oceanic biogeochemical controls on global dynamics of persistent organic pollutants. Environmental Science \& Technology, 36 (20), 4229-4237.

Dauvin, J.C., 2007. Fifty years of change. Marine Pollution Bulletin, 54, 1673-1676.

Derksen, C., Brown, R., 2012. Spring snow cover extent reductions in the 2008-2012 period exceeding climate model projections. Geophysical Research Letters, 39, L19504. doi:10.1029/2012GL053387.

Diez, R., Rigét, F.F., Sonne, C., Born, E.W., Bechshøft, T., McKinney, M.A., Drimmie, R.J., Muir, D.C.G., Letcher, R.J., 2013. Three decades (1983-2010) of contaminant trends in East Greenland polar bears (Ursus maritimus). Part 1: Legacy organochlorine contaminants. Environment International, 59, 485-493.

Diez, R., Gustavson, K., Sonne, C., Desforges, J.P., Riget, F.F., Pavlova, V., McKinney, M.A., Letcher, R.J., 2015. Physiologically-based pharmacokinetic modelling of immune, reproductive and carcinogenic effects from contaminant exposure in polar bears (Ursus maritimus) across the Arctic. Environmental Research, 140, 45-55.

Doick, K.J., Burauel, P., Jones, K.C., Semple, K.T., 2005. Distribution of aged C-14-PCB and $\mathrm{C}-14-\mathrm{PAH}$ residues in particle-size and humic fractions of an agricultural soil. Environmental Science \& Technology, 39, 6575-6583.

Domine, F., Cabanes, A., Legagneux, L., 2002. Structure, microphysics and surface area of the Arctic snow pack near Alert during ALERT 2000 campaign. Atmospheric Environment, 36, 2753-2765.

Donaldson, D.J., Anderson, D., 1999. Adsorption of atmospheric gases at the air-water interface, 2. C1eC4 alcohols, acids, and acetone. Journal of Physical Chemistry, A103, 871-876.

Duarte, C. M., Lenton, T. M., Wadhams, P. Wassmann, P., 2012. Abrupt climate change in the Arctic. Nature Climate Change, 2(2), 60-64.

Eckhardt, S., Breivik, K., Manø, S., Stohl, A., 2007. Record high peaks in PCB concentrations in the Arctic atmosphere due to long-range transport of biomass burning emissions. Atmospheric Chemistry and Physics, 7, 4527-4536. 
Enge, E.K., Heimstad, E.S., Kallenborn, R., 1998. Distribution of polychlorinated biphenyls (PCBs) in snow samples in northern Norway. Organochlorine Compounds, 39, 435-439.

Falkowski, P., Scholes, R.J., Boyle, E., Canadell, J., Canfield, D., Elser, J., Gruber, N., Hibbard, K., Hogberg, P., Linder, S., Mackenzie, F.T., Moore III, B., Pedersen, T., Rosenthal, Y., Seitzinger, S., Smetacker, V., Steffen, W., 2000. The global carbon cycles: a test of our knowledge of earth as a system. Science, 290, 291-296.

Finizio, A., Villa, S., Raffaele, F., Vighi, M., 2006. Variation of POP concentrations in fresh-fallen snow and air on an Alpine glacier (Monte Rosa). Ecotoxicology and Environmental Safety, 63, 25-32.

Flanner, M.G., Zender, C.S., Randerson, J.T., Rasch, P., 2007. Present-day climate forcing and response from black carbon in snow. Journal of Geophysical Research, 112, 345-349.

Foster, K.L., Stern, G.A., Pazerniuk, M.A., Hickie, B., Walkusz, W., Wang, F., Macdonald, R.W., 2012. Mercury biomagnification in marine zooplankton food webs in Hudson Bay. Environmental Science \& Technology, 46, 12952-12959.

French, T.D., Campbell, L.M., Jackson, D.C., Casselman, J.M., Scheider, W.A., Hayton, A., 2006. Long-term changes in legacy trace organic contaminants and mercury in Lake Ontario salmon in relation to source controls, trophodynamics, and climatic variability. Limnology and Oceanography, 51, 2794-2807.

Friedman, C.L., Zhang, Y.X., Selin, N.E., 2013. Climate change and emissions impacts on atmospheric PAH transport to the Arctic. Environmental Science \& Technology, 48(1), 429-437.

Friedman, C.L., Pierce, J.R., Selin, N.E., 2014. Assessing the influence of secondary organic versus primary carbonaceous aerosols on long-range atmospheric polycyclic aromatic hydrocarbon transport. Environmental Science \& Technology, 48(6), 3293-3302.

Friedman, C.L., Selin, N.E., 2016. PCBs in the Arctic atmosphere: determining important driving forces using a global atmospheric transport model. Atmospheric Chemistry and Physics, 16, 3433-3448.

Fuglei, E., Bustnes, J.O., Hop, H., Mork, T., Bjornfoth, H., van Bavel, B., 2007. Environmental contaminants in arctic foxes (Alopex lagopus) in Svalbard: relationships with feeding ecology and body condition. Environmental Pollution, 146, 128-138.

Gaden, A., Ferguson, S.H., Harwood, L., Melling, H., Stern, G.A., 2009. Mercury trends in ringed seals (Phoca hispida) from the western Canadian Arctic since 1973: Associations with length of ice-free season. Environmental Science \& Technology, 43, 3646-3651.

Galbán-Malagón, C., Berrojalbiz, N., Ojeda, M.J., Dachs, J., 2012. The oceanic biological pump modulates the atmospheric transport of persistent organic pollutants to the Arctic. Nature Communications, 3(3), 199-202. DOI: 10.1038/ncomms1858.

Gao, H., Ma, J., Cao, Z., Dove, A., Zhang, L., 2010. Trend and climate signals in seasonal air concentration of organochlorine pesticides over the Great Lakes. Journal of Geophysical Research, 115, D15307. DOI: 10.1029/2009JD013627.

Garrett, T.J., Zhao, C., 2006. Increased Arctic cloud longwave emissivity associated with pollution from mid-latitudes. Nature, 440 (7085),787-789.

Geisz, H.N., Dickhut, R.M., Cochran, M.A., Fraser, W.R., Ducklow, H.W., 2008. Melting glaciers: A probable source of DDT to the Antarctic marine ecosystem. Environmental Science \& Technology, 42, 3958-3962.

Gilbert, D., 2011. Buried by bad decisions. Nature, 474(7351), 275-277. 
Gioia, R., Lohmann, R., Dachs, J., Temme, C., Lakaschus, S., Schulz-Bull, D., Hand, I., Jones, K.C., 2008. Polychlorinated biphenyls in air and water of the North Atlantic and Arctic Ocean. Journal of Geophysical Research,113, D19302. DOI: 10.1029/2007JD009750.

Gobas, F.A.P.C., Graggen, M.N., Zhang, X., 1995. Time response of the Lake Ontario ecosystem to virtual elimination of PCBs. Environmental Science \& Technology, 29, 2038-2046.

Gobas, F.A.P.C., MacLean, L.G., 2003. Sediment-water distribution of organic contaminants in aquatic ecosystems: The role of organic carbon mineralization. Environmental Science \& Technology, 37, 735-741.

Goldberg, E.D., Bourne, W.R.P., Boucher, E.A., Preston, E., 1975. Synthetic organohalides in the sea. Proceedings of the Royal Society of London Series, 189, 277-289.

Goss, K.U., 1997. Conceptual model for the adsorption of organic compounds from the gas phase to liquid and solid surfaces. Environmental Science \& Technology, 31, 3600-3605.

Gouin, T., Armitage, J.M., Cousins, I.T., Muir, D.C.G., Ng, C.A., Reid, L., Tao, S., 2013. Influence of global climate change on chemical fate and bioaccumulation: The role of multimedia models. Environmental Toxicology and Chemistry, 32, 20-31.

Grannas, A.M., Bogdal, C., Hageman, K.J., Halsall, C., Harner, T., Hung, H., Kallenborn, R., Klan, P., Klanova, J., Macdonald, R.W., Meyer, T., Wania, F., 2013. The role of the global cryosphere in the fate of organic contaminants. Atmospheric Chemistry and Physics, 13, 3271-3305.

Grynkiewicz, M., Polkowska, Z., Gorecki, T., Namiesnik, J., 2001. Pesticides in precipitation in the Gdansk region (Poland). Chemosphere, 43, 303-312.

Grynkiewicz, M., Polkowska, Z., Namiesnik, J., 2002. Determination of polycyclic aromatic hydrocarbons in bulk precipitation and runoff waters in an urban region (Poland). Chemosphere, 36, 361-369.

Hanot, L., Donime, F., 1999. Evolution of the surface area of a snow layer. Environmental Science \& Technology, 33, 4250-4255.

Hansen, K.H, Christensen, J.H, Geels, C., Silver, J.D., Brandt, J., 2015. Modelling the impact of climate change on the atmospheric transport and the fate of persistent organic pollutants in the Arctic. Atmospheric Chemistry and Physics, 15, 6549-6559.

Heintzenberg, J., 1989. Arctic haze: air pollution in polar regions, AMBIO: A Journal of the Human Environment, 18, 50-55.

Henson, S.A., Sarmiento, J.L., Dunne, J.P., Bopp, L., Lima, I., Doney, S.C., John, J., Beaulieu, C., 2010. Detection of anthropogenic climate change in satellite records of ocean chlorophyll and productivity. Biogeosciences, 7, 621-640.

Herbert, B.M.J., Villa, S., Halsall C.J., 2006. Chemical interactions with snow: understanding the behaviour of semi-volatile organic compounds in snow. Ecotoxicology and Environmental Safety, 63, 3-16.

Hoekstra, P.F., O'Hara, T.M., Pallant, S., Solomon, K.R., Muir, D.C.G., 2002. Bioaccumulation of organochlorine contaminants in bowhead whales (Balaena mysticetus) from Barrow, Alaska. Archives of Environmental Contamination and Toxicology, 42, 497-507.

Hoerling, M.P., Hurrell, J.W., Xu, T., 2001. Tropical origins for recent North Atlantic climate change. Science, 292, 90-92.

Hoff, R.M., Strachan, W.M.J., Sweet, C.W., Chan, C.H., Shackleton, M., Bidleman, T.F., Brice, K.A., Burniston, D.A., Cussion, S., Gatz, D.F., Harlin, K., Schroeder, W.H., 1996. Atmospheric 
deposition of toxic chemicals to the Great Lakes: A review of data through 1994. Atmospheric Environment, 30, 3505-3527.

Holland, M.M., Bitz, C.M., Tremblay, B., 2006. Future abrupt reductions in the summer Arctic sea ice. Geophysical Research Letters, 2006, 33(23), 265-288.

Honjo, S., Krishfield, R.A., Eglinton, T.I., Manganini, S.J., Kemp, J.N., Doherty, K., Hwang, J., McKee, T.K., Takizawa, T., 2010. Biological pump processes in the cryopelagic and hemipelagic Arctic Ocean: Canada Basin and Chukchi Rise. Progress in Oceanography, 85, 137-170.

Houde, M., De Silva, A.O., Muir, D.C.G., Letche, R.J., 2011. Monitoring of perfluorinated compounds in aquatic biota: An updated review. Environmental Science \& Technology, 45, 7962-7973.

Hung, H., Blanchard, P., Halsall, C.J., Bidleman, T.F., Stern, G.A., Fellin, P., Muir, D.C.G., Barrie, L.A., Jantunen, L.M., Helm, P.A., Ma, J., Konoplev, A., 2005. Temporal and spatial variabilities of atmospheric POPs in the Canadian Arctic: Results from a decade of monitoring. Science of the Total Environment, 342, 119-144.

Hung, H., Kallenborn, R., Breivik, K., Su, Y., Brorström-Lundén, E., Olafsdottir, K., Thorlacius, J.M., Leppänen, S., Bossi, R., Skov, H., Manø, S., Patton, G.W., Stern, G., Sverko, E., Fellin, P., 2010. Atmospheric monitoring of organic pollutants in the Arctic under the Arctic Monitoring and Assessment Programme (AMAP): 1993-2006. Science of the Total Environment, 408, 2854-2873.

Hung, H., Katsoyiannis, A. A., Brorström-Lundén, E., Olafsdottir, K., Aas, W., Breivik, K., Bohlin-Nizzetto, P., Sigurdsson, A., Hakola, H., Bossi, R., Skov, H., Sverko, E., Barresi, E., Fellin, P., Wilson, S. (2016) Temporal Trends of Persistent Organic Pollutants (POPs) in Arctic Air: 20 Years of Monitoring under the Arctic Monitoring and Assessment Programme (AMAP). Environmental Pollution, Article in Press.

Hwang, J., Kim, M., Manganini, S.J., McIntyre, C.P., Haghipour, N., Park, J., Krishfield, R.A., Macdonald, R.W., McLaughlin, F.A., Eglinton, T.I., 2015. Temporal and spatial variability of particle transport in the deep Arctic Canada Basin. Journal of Geophysical Research-Oceans, $120,2784-2799$.

IPCC, 2005. Carbon dioxide capture and storage. Bert Metz, Ogunlade Davidson, Heleen de Coninck, Manuela Loos and Leo Meyer (Eds.) Cambridge University Press, UK. pp. 431

IPCC, 2013. Summary for Policy makers, in: Stocker, T.F., Qin, D., Plattner, G.-K., Tignor, M., Allen, S.K., Boschung, J., Nauels, A., Xia, Y., Bex, V., Midgley, P.M. (Eds.), Climate Change 2013: The Physical Science Basis. Contribution of Working Group I to the Fifth Assessment Report of the Intergovernmental Panel on Climate Change. Cambridge University Press, United Kingdom, pp. 28

Jantunen, L., and T. Bidleman, T.,. 1995. Reversal of the air-water gas exchange direction of hexachlorocyclohexanes in the Bering and Chukchi seas: 1993 versus 1988. Environmental Science and Technology, 29, 1081-1089.Jantunen, L., Bidleman, T. F., 2006. Henry's law constants for hexachlorobenzene, p,p'-DDE and components of technical chlordane and estimates of gas exchange for Lake Ontario. Chemosphere, 62, 1689-1696.

Jantunen, L.M., Helm, P.A., Kylin, H., Bidleman, T.F., 2008. Hexachlorocyclohexanes (HCHs) in the Canadian Archipelago. 2. Air-water gas exchange of a- and $\gamma-\mathrm{HCH}$. Environmental Science \& Technology, 42(2), 465-470.

Jenssen, B.M., 2006. Endocrine-disrupting chemicals and climate change: A worst-Case combination for Arctic marine mammals and seabirds? Environmental Health Perspectives, 14, 76-80. 
Jeremiason, J.D., Eisenreich, S.J., Baker, J.E., Eadie, B.J., 1998. PCB decline in settling particles and benthic recycling of PCBs and PAHs in Lake Superior. Environmental Science \& Technology, 32, 3249-3256.

Kallenborn, R., Macdonald, R., Halsall, C., Pawlak, J., Bidleman, T, 2011. Contaminant pathways and change in the cryosphere. Chapter 11.3. In Snow, water, ice and permafrost in the Arctic (SWIPA): Climate Change and the Cryosphere. Arctic Monitoring and Assessment Programme (AMAP), Oslo, Norway xii + 538 pp. Arctic Monitoring and Assessment Programme, Oslo, Norway. pp. 11-19 to 11-27.

Kallenborn, R., Halsall, C., Dellong, M., Carlsson, P., 2012. The influence of climate change on the global distribution and fate processes of anthropogenic persistent organic pollutants. Journal of Environment Monitoring, 4, 2854-2869.

Karhu, K., Auffret, M.D., Dungait, J.A.J., Hopkins, D.W., Prosser, J.I., Singh, B.K., Subke, J., Wookey, P.A., Agren, G.I., Sebastia, M.T., Gouriveau, F., Bergkvist, K., Meir, P., Nottingham, A.T., Salinas, N., Hartley, I.P., 2014. Temperature sensitivity of soil respiration rates enhanced by microbial community response. Nature, 513 (7516): 81-84. DOI: 10.1038/nature13604

Kelly, B.C., 2006. Bioaccumulation potential of organic contaminants in an arctic marine food web. $\mathrm{PhD}$ thesis, Simon Fraser University, available at http://summit.sfu.ca /item/2326.

Komprda, J., Komprdová, K., Sáňka, M.,Možný, M., Nizzetto, L., 2013. Influence of climate and land use change on spatially resolved volatilization of persistent organic pollutants (POPs) from background soils. Environmental Science \& Technology, 47, 7052-7059

Kong, D., MacLeod, M., Hung, H., Cousins, I. T., 2014. Statistical analysis of long-term monitoring data for persistent organic pollutants in the atmosphere at 20 monitoring stations broadly indicates declining concentrations. Environmental Science \& Technology, 48 (21), 12492-12499.

Lamon, L., von Waldow, H., MacLeod, M., Scheringer, M., Marcomini, A., Hungerbuhler, K., 2009. Modeling the global levels and distribution of polychlorinated biphenyls in air under a climate change scenario. Environmental Science \& Technology, 43, 5818-5824.

Lavoie, D., Denman, K.L. Macdonald, R.W., 2010. Effects of future climate change on primary productivity and export fluxes in the Beaufort Sea. Journal of Geophysical Research, 115, C04018.

Le Treut, H., Somerville, R., Cubasch, U., Ding, Y., Mauritzen, C., Mokssit, A., Peterson, T., Prather, M. et al., Historical Overview of Climate Change. In: Climate Change 2007: The Physical Science Basis. Contribution of Working Group I to the Fourth Assessment Report of the Intergovernmental Panel on Climate Change [Solomon, S., D. Qin, M. Manning, Z. Chen, M. Marquis, K.B. Averyt, M. Tignor and H.L. Miller (eds.)]. Cambridge University Press, Cambridge, United Kingdom and New York, NY, USA.

Lei, Y.D., Wania, F., 2004. Is rain or snow a more efficient scavenger of organic chemicals? Atmospheric Environment, 38, 3557-3571.

Lenton, T.M., 2011. Early warning of climate tipping points. Nature Climate Change, 1(4), 201-209.

Letcher, R.J., Bustnes, J.O., Dietz, R., Jenssen, B.M., Jørgensen, E.H., Sonne, C., Verreault, J., Vijayan, M.M., Gabrielsen, G.W., 2010. Exposure and effects assessment of persistent organohalogen contaminants in arctic wildlife and fish. Science of the Total Environment, 408, 2995-3043.

Li, Y.F., Macdonald, R.W., Jantunen, L.M.M., Harner, T., Bidleman, T.F., Strachan, W.M.J., 2002. The transport of beta-hexachlorocyclohexane to the western Arctic Ocean: a contrast to alpha-HCH. Science of the Total Environment, 291 (1-3), 229-246. 
Li, Y.F., Macdonald, R.W., Ma, J., Hung, H., Venkatesh, S., 2004. Historical a-HCH budget in the Arctic Ocean: The Arctic mass balance box model (AMBBM). Science of the Total Environment, 324, 115-139.

Li, Y.F., Macdonald, R.W., 2005. Sources of selected organochlorine pesticides in the Arctic and the effect of pathway divergence on $\mathrm{HCH}$ trends in biota: A review. Science of the Total Environment, 342, 87-106.

Li, N., Wania, F., Lei, Y. D., Daly, G. L., 2003. A comprehensive and critical compilation, evaluation, and selection of physical-chemical property data for selected polychlorinated biphenyls. Journal of Physical and Chemical Reference Data, 32, 1545-1590.

Livina, V.N., Lenton, T.M., 2013. A recent tipping point in the Arctic sea ice cover: abrupt and persistence increase in the seasonal cycle since 2007. Cryosphere, 7, 275-286.

Lohmann, R., Breivik, K., Dachs, J., Muir, D.C.G., 2007. Global fate of POPs: Current and future research directions. Environmental Pollution, 150, 150-165.

Loseto, L., Stern, G.A., Macdonald, R.W., 2015. Distant drivers or local signals: where do mercury trends in western Arctic belugas originate? Science of the Total Environment, 509-510, 226-236.

Lowry, K.E., van Dijken, G.L., Arrigo, K.R., 2014. Evidence of under-ice phytoplankton blooms in the Chukchi Sea from 1998 to 2012. Deep-Sea Research Part II-Topical Studies in Oceanography, 105, 105-117.

Luchin, V., Paneled, G., 2014. Thermal regimes in the Chukchi sea from 1941-2008. Deep-Sea Research II, 109, 14-26.

Lucia, M., Verboven, N., Strom, H., Miljeteig, C., Gavrilo, M.V., Braune, B.M., Boertmann, D., Gabrielsen, G.W., 2015. Circumpolar contamination in eggs of the High-Arctic ivory gull Pagophila ebunea. Environmental Toxicology and Chemistry, 34, 1552-1561.

Ma, J., Venkatesh, S., Jantunen, L. M. M. 2003. Evidence of the impact of ENSO events on temporal trends of Hexachlorobenzene air concentrations over the Great Lakes, Science of the Total Environment, 313(1-3), 177-184.

Ma, J., Hung, H., Blanchard, P., 2004a. How do climate fluctuations affect persistent organic pollutant distribution in North America? Evidence from a decade of air monitoring. Environment Science $\&$ Technology, 38, 2538-2543.

Ma, J., Cao, Z., Hung, H., 2004b. North Atlantic Oscillation signatures in the atmospheric concentrations of persistent organic pollutants-An analysis using Integrated Atmospheric Deposition Network-Great Lakes data. Journal of Geophysical Research-Atmosphere, 109, D12305, doi: 10.1029/2003JD004435.

Ma, J., Venkatesh, S., Li, Y., Cao, Z., Daggupaty, S.M., 2005. Tracking toxaphene in the North American Great Lakes basin - 2. A strong episodic long-range transport event. Environmental Science \& Technology, 39, 8123-8131.

Ma, J., Li, Y., 2006. Interannual variation of persistent organic pollutants over the Great Lakes induced by tropical Pacific sea surface temperature anomalies. Journal of Geophysical Research, 111, D04302, doi:10.1029/2005JD006014.

Ma, J., 2010. Atmospheric transport of persistent semi-volatile organic chemicals to the Arctic and cold condensation in the mid-troposphere-Part 1: 2-D modeling in mean atmosphere. Atmospheric Chemistry and Physics, 10, 7303-7314.

Ma, J., Cao, Z., 2010. Quantifying the perturbations of persistent organic pollutants induced by climate change. Environmental Science \& Technology, 44, 8567-8573. 
Ma, J., Hung, H., Tian, C., Kallenborn, R., 2011. Revolatilization of persistent organic pollutants in the Arctic induced by climate change. Nature Climate Change, 1, 256-260.

Ma, J., Sverko, E., Su., Yu., Zhang, J., Gao, H., 2013. Uptake and mobilization of organic chemicals with clouds: Evidence from a hail sample. Environmental Science \& Technology, 47, 9715-9721.

Macdonald, R.W., Bewers, J.M., 1996. Contaminants in the arctic marine environment: priorities for protection. ICES Journal of Marine Science, 53, 537-563.

Macdonald, R.W., Mackay, D., Hickie, B., 2002. Contaminant amplification in the environment: Revealing the fundamental mechanisms. Environmental Science \& Technology, 36, 457A-462A.

Macdonald, R.W., Mackay, D., Li, Y.F., Hickie, B., 2003. How will global climate change affect risks from long-range transport of persistent organic pollutants? Human and Ecological Risk Assessment, 9(3), 643-660.

Macdonald, R.W., Harner T., Fyfe, J., 2005. Recent climate change in the Arctic and its impact on contaminant pathways and interpretation of temporal trend data. Science of the Total Environment, 342, 5-86.

Macdonald, R.W., 2007. Contaminants, climate change and cold regions, in: Orbaek, J.B., Tombre, I., Kallenborn, R., Heggseth, E.N., Falk-Petersen, S., Hoel, A.H. (Eds.), Arctic-Alpine Ecosystems and People in a Changing Environment. Springer-Verlag, Berlin, pp. 305-327.

Macdonald, R.W., Kuzyk, Z.A., Johannessen, S.C., 2015. It is not just about the ice: A geochemical perspective on the changing Arctic Ocean. Journal of Environmental Studies and Sciences, 5, 288-301.

Mackay, D., Sang, S., Vlahos, P., Diamond, D., Gobas, F., Dolan, D., 1994. A rate constant model of chemical dynamics in a lake ecosystem: PCBs in Lake Ontario. Journal of Great Lakes Research, 20, 625-642.

Mackay, D., Wania, F., 1995. Transport of contaminants to the Arctic: partitioning, processes and models. Science of the Total Environment, 160-161, 25-38.

Mackay, D., 2001. Multimedia Environmental Models: the fugacity approach, $2^{\text {nd }}$ Edition, Lewis Publishers, New York, pp. 261

MacLeod, M., Riley, W.J., Mckone, T.E., 2005. Assessing the influence of climate variability on atmospheric concentrations of polychlorinated biphenyls using a Global-Scale Mass Balance Model (BETR-Global). Environmental Science \& Technology, 39, 6749-6756.

Manciocco, A., Calamandrei, G., Alleva, E., 2014. Global warming and environmental contaminants in aquatic organisms: The need of the etho-toxicology approach. Chemosphere, 100, 1-7.

Mao, X., Gao, H., Huang, T., Zhang, L., Ma, J., 2014. Modeling global persistent organic chemicals in clouds. Atmospheric Environment, 96, 345-352.

Masson, O., Baeza, A., Bieringer, J., Brudecki, K., Bucci, S., Cappai, M., Carvalho, F.P., Connan, O., Cosma, C., Dalheimer, A., Didier, D., Depuydt, G., De Geer, L.E., De Vismes, A., Gini, L., Groppi, F., Gudnason, K., Gurriaran, R., Hainz, D., Halldorsson, O., Hammond, D., Hanley, O., Holey, K., Homoki, Z., Ioannidou, A., Isajenko, K., Jankovic, M., Katzlberger, C., Kettunen, M., Kierepko, R., Kontro, R., Kwawman, P.J.M., Lecomte, M., Leon Vintro,L., . Leppanen, A.P., Lind, B., Lujaniene, G., Mc Ginnity, R., Mc Mahon, C., Mala, H., Manenti, S., Manolopoulou, M., Mattila, A., Mauringm, A., Papastefanou, C., Penev, I., Pham, M.K., Povinec, P.P., Rameback, H., Reis, M.C., Ringer, W., Rodriguez, A., Rulík, P., Saey, P.R.J., Samsonov, V., Schlosser, C., Sgorbati, G., Silobritiene, B.V., Soderstrom, C., Sogni, R., Solier, L., Sonck, M., Steinhauser, G., Steinkopf, T., Steinmann, P., Stoulos, S., Sykora, I., 
Todorovic, D., Tooloutalaie, N., Tositti, L., Tschiersch, J., Ugron, A., Vagena, E., Vargas, A., Wershofen, H., Zhukova, O., 2011. Tracking of airborne radionuclides from the damaged Fukushima Dai-Ichi Nuclear Reactors by European Networks. Environmental Science \& Technology, 45, 7670-7677.

McGuire, A.D., Anderson, L.G., Christensen, T.R., Dallimore, S., Guo, L., Hayes, D.J., Heimann, M., Lorenson, T.D., Macdonald, R.W., Roulet, N., 2009. Sensitivity of the carbon cycle in the Arctic to climate change. Ecological Monographs, 79(4), 523-555.

McKinney, M.A., Peacock, E., Letcher, R.J., 2009. Sea ice-associated diet change increases the levels of contaminants in polar bears. Environmental Science \& Technology, 43, 4334-4339.

McKinney, M.A., McMeans, B.C., Tomy, G.T., Rosenberg, B., Ferguson, S.H., Morris, A., Muir, D.C.G., Fisk, A.T., 2012. Trophic transfer of contaminants in a changing arctic marine food web: Cumberland Sound, Nunavut, Canada. Environmental Science \& Technology, 46, 9914-9922.

McKinney, M.A., Iverson, S.J., Fisk, A.T., Sonne, C., Rigét, F.F., Letcher, R.J., Arts, M.T., Born, E.W., Rosing-Asvid, A., Dietz, R., 2013. Global change effects on the long-term feeding ecology and contaminant exposures of East Greenland polar bears. Global Change Biology, 19 (8), 2360-2372. DOI: $10.1111 / \mathrm{gcb} .12241$.

McKinney, M.A., Pedro, S., Dietz, R., Sonne, C., Fisk, A.T., Roy, D., Jenssen, B.M., Letcher, R.J., 2015. A review of ecological impacts of global climate change on persistent organic pollutant and mercury pathways and exposures in arctic marine ecosystems. Current Zoology, 61, 617-628.

McKone, T.E., Daniels, J.I., Goldman, M., 1996. Uncertainties in the link between global climate change and predicted health risks from pollution: Hexachlorobenzene (HCB) case study using a fugacity model. Risk Analysis, 16(3): 377-393.

Meijer, S.N., Ockenden, W.A., Sweetnam, A., Breivik, K., Grimalt, J.O., Jones, K.C., 2003. Global distribution and budget of PCBs and HCB in background surface soils: implications for sources and environmental processes. Environmental Science \& Technology, 37, 667-672.

Meijer, S., Grimalt, J., Fernandez, P., Dachs, J., 2009. Seasonal fluxes and temperature-dependent accumulation of persistent organic pollutants in lakes: The role of internal biogeochemical cycling. Environmental Pollution, 157, 1815-1822.

Meyer, T., Wania, F., 2008. Organic contaminant amplification during snowmelt. Water Research, 42, 1847-1865.

Moeckel, C., Nizzetto, L., Guardo, A.D., Steinnes, E., Freppaz, M., Filippa, G., Camporini, Paolo., Benner, J., Jones, K.C., 2008. Persistent organic pollutants in boreal and montane soil profiles: distribution, evidence of processes, and implications for global cycling. Environmental Science \& Technology, 42(22), 8374-8380

Moeckel, C., Nizzetto, L., Berg, B., Lindroth, A., Jones, K.C., 2009. Air-boreal forest transfer and processing of polychlorinated biphenyls. Environmental Science \& Technology, 43(14), $5282-5289$

Muir, D.C.G., Norstrom, R.J., 1994. Persistent organic contaminants in Arctic marine and freshwater ecosystems. Arctic Research of the United States, 8, 136-146.

Muir, D., Riget, F., Cleemann, M., Skaare, J., Kleivane, L., Nakata, H., Dietz, R., Severinsen, T., Tanabe, S., 2000. Circumpolar trends of PCB and organochlorine pesticides in the arctic marine environment inferred from levels in ringed seals. Environmental Science \& Technology, 34(12), 2431-2438. 
Müller-Herold, U., Caderas, U., Funck, P., 1997. Validity of global lifetime estimates by a simple general limiting law for the decay of organic compounds with long-range pollution potential. Environmental Science \& Technology, 31, 3511-3515.

Bengtson Nash, S., 2011. Persistent organic pollutants in Antarctica: current and future research priorities. Journal of Environmental Monitoring, 13, 497-504.

NCP, 2013. Canadian Arctic Contaminants Assessment Report On Persistent Organic Pollutants 2013.Muir D, Kurt-Karakus P, Stow J. (Eds). Northern Contaminants Program, Aboriginal Affairs and Northern Development Canada, Ottawa ON. xxiii + 487 pp + Annex.

$\mathrm{Ng}$, C.A., Gray, K.A., 2011. Forecasting the effects of global change scenarios on bioaccumulation patterns in great lakes species. Global Change Biology, 17, 720-733

Nizzetto, L., Jarvis, A., Brivio, P.A., Jones, K.C., Di Guardo, A., 2008. Seasonality of air-forest canopy POP exchange. Environmental Science \& Technology, 42, 8778-8783.

Nizzetto, L., MacLeod, M., Borga, K., Cabrerizo, A., Dachs, J., Guardo, A.D., Ghirardello, D., Hansen, K.M., Jarvis, A., Lindroth, A., Ludwig, B., Monteith, D., Perlinger, J.A., Scheringer, M., Schwendenmann, L., Semple, K.t., Wick, L.Y., Zhang, G., Jones, K.C., 2010. Past, present, and future controls on levels of persistent organic pollutants in the global environment. Environmental Science \& Technology, 44, 6526-6531.

Nizzetto, L., Gioia, R., Li, J., Borgå, K., Pomati, F., Bettinetti, R., Dachs, J., Jones, K.C., 2012. Biological pump control of the fate and distribution of hydrophobic organic pollutants in water and plankton. Environmental Science \& Technology, 46, 3204-3211.

Noyes, P.D., McElwee, M.K., Miller, H.D., Clark, B.W., Van Tiem, L.A., Walcott, K.C., Erwin, K.N., Levin, E.D., 2009. The toxicology of climate change: environmental contaminants in a warming world. Environment International, 35, 971-986.

Noyes, P.D., Lima, S.C., 2015. Forecasting the impacts of chemical pollution and climate change interactions on the health of wildlife. Current Zoology, 61. 669-689.

O’Driscoll, K., Mayer, B., Su, J., Mathis, M., 2014. The effects of climate change on persistent organic pollutants (POPs) in the North Sea. Ocean Science, 10, 397-409.

Octaviani, M., Stemmler, I., Lammel, G., Graf, F., 2015. Atmospheric transport of persistent organic pollutants to and from the Arctic under present-day and future climate. Environmental Science \& Technology, 49(6), 3593-3602.

Ottar, B., 1981. The transfer of airborne pollutants to the Arctic region. Atmospheric Environment, 15, 1439-1445.

Overpeck, J.T., Sturm, M., Francis, J.A., Perovich, D.K., Serreze, M.C., Benner, R., Carmack, E.C., Chapiun III, F.S., Gerlach, S.C., Hamilton, L.C., Hinzman, L.D., Holland, M., Huntington, H.P., Key, J.R., Lloyd, A.H., Macdonald, G.M., McFadden, J., Noone, D., Prowse, T.D., Schlosser, P., Vörösmarty, C., 2005. Arctic system on trajectory to new, seasonally ice-free state. EOS, Transactions, American Geophysical Union, 86, 309-316.

Pachauri, R., Reisinger, A., IPCC Climate Change 2007: Synthesis Report. Cambridge Univ. Press, 2007. Available at http://www.ipcc.ch/publications_ and_data/ publications_and_ data_reports.shtml.

Pacyna, J.M., Cousins, I.T., Halsall, C., Rautio, A., Pawlak, J., Pacyna, E.G., Sundseth, K., Wilson, S., Munthe, J., 2015. Impacts on human health in the Arctic owing to climate-induced changes in contaminant cycling - The EU ArcRisk project policy outcome. Environmental Science \& Policy, 50, 200-213.Palmer, M.A., Saenz, B.T., Arrigo, K.R., 2014. Impacts of sea ice retreat, thinning, and melt pond proliferation on the summer phytoplankton bloom in the Chukchi Sea, Arctic Ocean. Deep-Sea Research II, 105, 85-104. 
Pekar, M., Pavlova, N., Gusev, A., Shatalov, V., Vulikh, N., Ioannisian, D., Dutchak, S., Berg, T., Hjellbrekke, A., 1999. Long-range transport of selected persistent organic pollutants. Development of transport models for polychlorinated biphenyls, benzo[a]pyrene, dioxins/furans and lindane, Joint report of EMEP Centres: MSC-E and CCC, EMEP Report $4 / 99$.

Prentice, I.C., 2001. The carbon cycle and atmospheric carbon dioxide. In: Climate Change 2001: The Scientific Basis (IPCC). Cambridge: Cambridge University Press, pp.184-237

Pućko, M., Stern, G.A., MacDonald, R., Barner, D., 2010a. $\alpha$ - and $\gamma$-Hexachlorocyclohexane measurements in the brine fraction of sea ice in the Canadian High Arctic using a sump-hole technique. Environmental Science \& Technology, 44, 9258-9264.

Pućko, M., Stern, G.A., Barber, D.G., Macdonald, R.W., Rosenberg, B., 2010b. The International Polar Year (IPY) Circumpolar Flaw Lead (CFL) System Study: the importance of brine processes for $\alpha$ - and $\beta$-hexachlorocyclohexane $(\mathrm{HCH})$ accumulation/rejection in the sea ice. Atmosphere-Ocean, 48, 244-262.

Pućko, M., Stern, G.A., Macdonald, R.W., Barber, D.G., Rosenberg, B., 2011. The influence of the atmosphere-snow-ice-ocean interactions on the levels of hexachlorocyclohexanes (HCHs) in the Arctic cryosphere. Journal of Geophysical Research, 116, C02035.doi:10.1029/2010JC00661.

Pućko, M., Macdonald, R.W., Barber, D.G., Rosenberg, B., Gratton, Y., 2012a. $\alpha$-HCH enantiomer fraction (EF) - a novel approach to calculate the ventilation age of water in the Arctic Ocean? Journal of Geophysical Research, 117, C08038.

Pućko, M., Stern, G.A., Barber, D., Macdonald, R.W., Warner, K., Fuchs, C., 2012b. Mechanisms and implications of $\alpha-\mathrm{HCH}$ enrichment in melt pond water on Arctic sea ice. Environmental Science \& Technology, 46, 11862-11869.

Pućko, M., Stern, G.A., Macdonald, R.W., Barber, D.G., Rosenberg, B., Walkusz, W., 2013a. When will $\alpha-\mathrm{HCH}$ disappear from the Arctic Ocean? Journal of Marine Systems, 127, 88-100.

Pućko, M., Walkusz, W., Macdonald, R.W., Barber, D., Fuchs, C., Stern, G.A., 2013b. Importance of arctic zooplankton seasonal migrations for $\alpha$-hexachlorocyclohexane $(\alpha-\mathrm{HCH})$ bioaccumulation dynamics. Environmental Science \& Technology, 46, 11862-11869.

Pućko, M., Stern, G.A., Macdonald, R.W., Jantunen, L.M., Bidleman, T.F., Wong, F., Barber, D.G., Rysgaard, S., 2015. The delivery of organic contaminants to the Arctic food web: why sea ice matters. Science of the Total Environment, 506-507, 444-452.

Rahn, K.A., Heidam, N.Z., 1981. Progress in Arctic air chemistry 1977-1980: a comparison of the first and second symposium. Atmospheric Environment, 15, 1345-1348.

Rigét, F., Bignert, A., Braune, B., Stow, J., Wilson, S., 2010. Temporal trends of legacy POPs in Arctic biota, an update. Science of the Total Environment, 408, 2874-2884.

Rigét, F., Vorkamp, K., Hobson, K.A., Muir, D.C.G., Dietz, R., 2013. Temporal trends of selected POPs and the potential influence of climate variability in a Greenland ringed seal population. Environmental Science: Processes \& Impacts, 15, 1706-1716.

Rockström, J., Steffen, W., Noone, K., Persson, A., Chapin, S., Lambin, E.F., Lenton, T.M., Scheffer, M., Folke, C., Schellnhuber, H.J., Nykvist, B., de Wit, C.A., Hughes, T., van der Leeuw, S., Rodhe, H., Sörlin, S., Snyder, P.K., Costanza, R., Svedin, U., Falkenmark, M., Karlberg, L., Corell, R.W., Fabry, V.J., Hansen, J., Walker, B., Liverman, D., Richardson, K., Crutzen, P. Foley, J.A., 2009a. A safe operating space for humanity. Nature, 461 (24 September): 472-475. 
Rockström, J., Steffen, W., Noone, K., Persson, A., Chapin, S., Lambin, E.F., Lenton, T.M., Scheffer, M., Folke, C., Schellnhuber, H.J., Nykvist, B., de Wit, C.A., Hughes, T., van der Leeuw, S., Rodhe, H., Sörlin, S., Snyder, P.K., Costanza, R., Svedin, U., Falkenmark, M., Karlberg, L., Corell, R.W., Fabry, V.J., Hansen, J., Walker, B., Liverman, D., Richardson, K., Crutzen, P., Foley, J.A., 2009b. Planetary boundaries: Exploring the safe operating space for humanity. Ecology and Society, 14, 32.

Roemmich, D., Church, J., Gibson, J., Monselesan, D., Sutton, P., Wijfels, S., 2015. Unabated planetary warming and its ocean structure since 2006. Nature Climate Change, 5, 240-245.

Ross, P.S., Kennedy, C., Shelley, L.K., Tierney, K.B., Patterson, D.A., Fairchild, W.L., Macdonald, R.W., 2013. The trouble with salmon: Relating pollutant exposure to toxic effect in species with transformational life histories and lengthy migrations. Canadian Journal of Fisheries and Aquatic Sciences, 70, 1252-1264.

Roth, C.M., Goss, K. U., Schwarzenbach, R.P., 2002. Adsorption of a diverse set of organic vapors on the bulk water surface. Journal of Colloid Interface Science, 252, 21-30.

Roth, C.M., Goss, K.U., Schwarzenbach, R.P., 2004. Sorption of diverse organic vapors to snow. Environmental Science \& Technology, 38, 4078-4084.

RSC (The Royal Society), 2005. Ocean acidification due to increasing atmospheric carbon dioxide, Plymouth, UK, pp. 57

Schenker, U., MacLeod, M., Scheringer, M., Hungerbuhler, K., 2005. Improving data quality for environmental fate models: a least-squares adjustment procedure for harmonizing physicochemical properties of organic compounds. Environment Science \& Technology, 39, 8434-8441.

Scheringer, M., 1997. Characterization of the environmental distribution behaviour of organic chemicals by means of persistence and spatial range. Environmental Science \& Technology, 31, 2891-2897.

Scheringer, M., Hungerbühler, K., Matthies, M., 2001. The spatial scale of organic chemicals in multimedia fate modeling- Recent developments and significance for chemical.. Environmental Science and Pollution Research, 8, 150-155

Schiedek, D., Sundelin, B., Readman, J.W., Macdonald, R.W., 2007. Interactions between climate change and contaminants. Marine Pollution Bulletin, 54, 1845-1856.

Schindler, D.W., Smol, J.P., 2006. Cumulative effects of climate warming and other human on freshwaters of Arctic and subarctic freshwaters of North America. AMBIO: A Journal of the Human Environment ,35(4), 160-168.

Semple, K.T., Doick, K.J., Wick, L.Y., Harms, H., 2007. Microbial interactions with organic contaminants in soil: definitions, processes and measurement. Environmental Pollution, 150(1), 166-176.

Serreze, M.C., Walsh, J.E., Chapin, F.S.I., Osterkamp, T., Dyurgerov, M., Romanovsky, V., Oechel, W.C., Morison, J., Zhang, T., Barry, R.G., 2000. Observational evidence of recent change in the northern high-latitude environment. Climatic Change, 46, 159-207.

Serreze, M.C., Stroeve, J., 2015. Arctic sea ice trends, variability and implications for seasonal ice forecasting. Philosophical Transactions of the Royal Society a-Mathematical Physical and Engineering Sciences, 373.

Shen, L., Wania, F., Lei, Y.D., Teixeira, C., Muir, D.C.G., Bidleman, T.F., 2004. Hexachlorocyclohexanes in the North American atmosphere. Environmental Science \& Technology, 38, 965-975. 
Shen, L., Wania, F., 2005. Compilation, evaluation, and selection of physical-chemical property data for organochlorine pesticides. Journal of Chemical Engineering Data, 50, 742-768.

Shoeib, M., Harner, T., 2002. Using measured octanol-air partition coefficients to explain environmental partitioning of organochlorine pesticides. Environmental Toxicology and Chemistry, 21(5), 984- 990.

Simonich, S.L., Hites, R., 1994. Importance of vegetation in removing polycyclic aromatic hydrocarbons from the atmosphere. Nature, 370, 49-51

Simonich, S.L., Hites, R.A., 1995. Global distribution of persistent organochlorine compounds. Science, 269, 1851-1854.

Smith, J.N., Brown, R.M., Williams, W.J., Robert, M., Nelson, R., Moran, S.B., 2015. Arrival of the Fukushima radioactivity plume in North American continental waters. Proceedings of the National Academy of Sciences of the United States of America, 112, 1310-1315.

Sobek, A., Gustafsson, O., 2014. Deep water masses and sediments are main compartments for PCBs in the Arctic Ocean. Environmental Science \& Technology, 48, 6719-6725.

Steele, M., Ermold, W., Zhang, J., 2008. Arctic Ocean surface warming trends over the past 100 years. Geophysical Research Letter, 35, L0261.

Stemmler, I., Lammel, G., 2009. Cycling of DDT in the global oceans 1950-2002: World ocean returns the pollutant. Geophysical Research Letters, 36, L24602.

Stern, G.A., Braekevelt, E., Helm, P.A, Bidleman, T.F., Outridge, P.M., Lockhart, W.L., McNeeley, R., Rosenberg, B., Ikonomou, M.G., Hamilton, P., Tomy, G.T. Wikinson, P., 2005. Modern and historical fluxes of halogenated organic contaminants to a lake in the Canadian Arctic as determined from annually laminated sediment cores. Science of the Total Environment, 342(1-3): 223-243.

Stocker, J., Scheringer, M., Wegmann, F., Hungerbuhler, K., 2007. Modeling the effect of snow and ice on the global environmental fate and long-range transport potential of semivolatile organic compounds. Environmental Science \& Technology, 41, 6192-6198.

Stohl, A., Seibert, P., Wotawa, G., Arnold, D., Burkhart, J.F., Eckhardt, S., Tapia, C., Vargas, A., Yasunari, T.J., 2012. Xenon-133 and caesium-137 releases into the atmosphere from the Fukushima Dai-ichi nuclear power plant: determination of the source term, atmospheric dispersion, and deposition. Atmospheric Chemistry and Physics, 12, 2313-2343.

Stroeve, J.C., Kattsov, V., Barrett, A., Serreze, M., Pavlova, T., Holland, M., Meier, W.N., 2012. Trends in Arctic sea ice extent from CMIP5, CMIP3 and observations. Geophysical Research Letters, 39, L16502.

Sumaila, U.R., Cheung, W.W.L., Lam, V.W.Y., Pauly, D., Herrick, S., 2011. Climate change impacts on the biophysics and economics of world fisheries. Nature Climate Change, 1, 449-456.

Teng, Y., Xu, Z., Luo, Y., 2012. How do persistent organic pollutants be coupled with biogeochemical cycles of carbon and nutrients in terrestrial ecosystems under global climate change? Journal of Soils and Sediments, 12, 411-419.

Teran, T., Lamon, L., Marcomini, M., 2012. Climate change effects on POPs' environmental behaviour: a scientific perspective for future regulatory actions. Atmospheric Pollution Research, 3(4), 466-476.

Thies, H., Kickus, U., Mair, V., Tessadri, R., Tait, D., Thaler, B., Psenner, R., 2007. Unexpected response of high alpine lake waters to climate warming. Environmental Science \& Technology, 41, 7424-7429. 
Timothy, D.A., Wong, C.S., Barwell-Clarke, J.E., White, L.A., Page, J.S., Macdonald, R.W., 2013. Climatology of sediment flux and composition in the subarctic Northeast Pacific Ocean with biogeochemical implications. Progress in Oceanography, 116, 95-129.

UNEP/AMAP, 2011. Climate Change and POPs: Predicting the Impacts. Report of the UNEP/AMAP Expert Group. Secretariat of the Stockholm Convention, Geneva, pp. 62

van Pul, W., de Leeuw, F., van Jaarsveld, J., van der Gagg, M., Sliggers, C., 1998. The potential for long-range transboundary atmospheric transport. Chemosphere, 37, 113-141.

Villa, S., Negrelli, C., Finizio, A., Flora, O., Vighi, M., 2006. Organochlorine compounds in ice melt water from Italian Alpine rivers. Ecotoxicology and Environmental Safety, 63, 84-90.

von Waldow, H., MacLeod, M., Jones, K., Scheringer, M., Hungerbühler, K., 2010. Remoteness from emission sources explains the fractionation pattern of polychlorinated biphenyls in the Northern Hemisphere. Environmental Science \& Technology, 44, 6183-6188.

Vorkamp, K., Christensen, J.H., Rigét, F., 2004. Polybrominated diphenyl ethers and organochlorine compounds in biota from the marine environment of East Greenland. Science of the Total Environment, 331, 143-155.

Vorkamp, K., Rigét, F.F., Bossi, R., Dietz, R., 2011. Temporal trends of hexabromocyclododecane, polybrominated diphenyl ethers and polychlorinated biphenyls in ringed seals from East Greenland. Environmental Science \& Technology, 45, 1243-1249.

Wallace, J.M., Thompson, D.W.J., 2002. Annular modes and climate prediction. Physics Today, 55, $28-33$.

Wang, X., Gong, P., Zhang, Q., Yao, T., 2010a. Impact of climate fluctuations on deposition of DDT and hexachlorocyclohexane in mountain glaciers: Evidence from ice core records. Environmental Pollution, 158(2), 375-380.

Wang, F., Macdonald, R.W., Stern, G.A., Outridge, P.M., 2010b. When noise becomes the signal: Chemical contamination of aquatic ecosystems under a changing climate. Marine Pollution Bulletin, 60, 1633-1635.

Wania, F., Mackay, D., 1993. Global fractionation and cold condensation of low volatility organochlorine compounds in polar regions. AMBIO: A Journal of the Human Environment, $22,10-18$.

Wania, F., Mackay, D., 1996. Tracking the distribution of persistent organic pollutants. Environmental Science \& Technology, 30, 390-396A.

Wania, F., 1997. Modelling the fate of non-polar organic chemicals in an ageing snow pack. Chemosphere, 35, 2345-2363.

Wania, F., Haugen, J., Lei, Y., Mackay, 1998. Temperature dependence of atmospheric concentrations of semivolatile organic compounds. Environmental Science \& Technology, 32, 1013-1021.

Wania, F., Mackay, D., 1999. Global chemical fate of a-hexachlorocyclohexane. 2. Use of a global distribution model for mass balancing, source apportionment, and trend prediction. Environmental Toxicology and Chemistry, 18, 1400-1407.

Wania, F., 2003. Assessing the potential of persistent organic chemicals for long-range transport and accumulation in polar regions. Environmental Science \& Technology 37, 1344-1351.

Wania, F., Su. Y., 2004. Quantifying the global fractionation of polychlorinated biphenyls. AMBIO, 33(3), 161-168.

Watson, R.T., Patz, J., Gubler, D.J., Parson, E.A., Vincent, J.H., 2005. Environmental health implications of global climate change. Journal of Environmental Monitoring, 7, 834-843. 
Weingartner, T.J., Danielson, S., Sasaki, Y., Pavlov, V., Kulakov, M., 1999. The Siberian coastal current: A wind- and buoyancy-forced Arctic coastal current. Journal of Geophysical Research, 104, 29697-29713.

Wöhrnschimmel, H., MacLeod, M., Hungerbühler, K., 2013. Emissions, fate and transport of persistent organic pollutants to the Arctic in a changing global climate. Environmental Science \& Technology, 47, 2323-2330.

Wong, F., Jantunen, L. M., Pućko, M., Papakyriakou, T., Stern, G. A., Bidleman, T. F., 2010. Air-water exchange of anthropogenic and natural organohalogenson: International Polar Year (IPY) expeditionsin the Canadian Arctic. Environmental Science \& Technology, 45, 876-881.

Wood, K.R., Bond, N.A., Danielson, S.L., Overland, J.E., Salo, S.A., Stabeno, P., Whitefield, J., 2015. A decade of environmental change in the Pacific Arctic region. Progress in Oceanography, $136,12-31$.

Woodgate, R.A., Aagaard, K., Wiengartner, T.J., 2006. Interannual changes in the Bering Strait fluxes of volume, heat and freshwater between 1991 and 2004. Geophysical Research Letters 33, L15609.

World Health Organization. Persistent Organic Pollutants: Impact on Child Health. 2010. Geneva, Switzerland, pp. 59

Xiao, H., Li, N.Q., Wania, F., 2004. Compilation, evaluation, and selection of physical-chemical property data for alpha-, beta-, and gamma-hexachlorocyclohexane. Journal of Chemical Engineering Data, 49, 173-185.

Xu, Z.H., Chen, C.R., 2006. Fingerprinting global climate change and forest management within rhizosphere carbon and nutrient cycling processes. Environmental Science and Pollution Research, 13, 293-298.

Yao, Y., Harner, T. Ma, J., Tuduri, L., Blanchard, P., 2007. Sources and occurrence of Dacthal in the Canadian atmosphere. Environmental Science \& Technology, 41(3), 688-694.

Zhang, L., Ma, J., Venkatesh, S., Li, Y., Cheung, P., 2008. Modeling evidence of episodic intercontinental long-range transport of lindane. Environmental Science \& Technology, 42, 8791-8797.

Zhang, L., Lohmann, R., 2010. Cycling of PCBs and HCB in the surface ocean-lower atmosphere of the open pacific. Environmental Science \& Technology, 44(10), 3832-3838.

Zhang, Y., Jacob, D.J., Dutkiewicz, S., Amos, H.M., Long, M.S., Sunderland, E.M., 2015. Biogeochemical drivers of the fate of riverine mercury discharged to the global and Arctic Oceans. Global Biogeochemical Cycles, 29, 854-864. doi:10.1002/2015GB005124.

Zhao, Y., Huang, T., Gao, H., Ma, J., 2015. Step changes in persistent organic pollutants over the Arctic and their implications. Atmospheric Chemistry and Physics, 15, 3479-3495.

Zheng, Q., Nizzetto, L., Mulder, M.D., Sáňka, O., Lammel, G., Li, J., Bing, H., Liu, X., Jiang, Y., Luo, C., Zhang, G., 2014. Does an analysis of polychlorinated biphenyl (PCB) distribution in mountain soils across China reveal a latitudinal fractionation paradox? Environmental Pollution, 195, 115-122. 